\title{
Rimicaris exoculata: biology and ecology of a shrimp from deep-sea hydrothermal vents associated with ectosymbiotic bacteria
}

\author{
Magali Zbinden $^{1, *}$, Marie-Anne Cambon-Bonavita ${ }^{2}$ \\ ${ }^{1}$ Sorbonne Université, Univ Paris 06, UMR CNRS MNHN 7208 Biologie des Organismes Aquatiques et Ecosystèmes (BOREA), \\ Equipe Adaptation aux Milieux Extrêmes, 75005 Paris, France \\ ${ }^{2}$ Univ Brest, Ifremer, CNRS, Laboratoire de Microbiologie des Environnements Extrêmes, 29280 Plouzané, France
}

\begin{abstract}
Rimicaris exoculata, the 'blind shrimp,' is the most abundant species living on active hydrothermal edifices at deep-sea vents of the Mid-Atlantic Ridge. Its unusually enlarged branchial chamber houses a dense ectosymbiotic community of chemoautotrophic bacteria. Long debated, shrimp nutrition has been proven to be a kind of osmotrophy, whereby small organic molecules produced by the symbionts pass through the integument of the shrimp directly into the circulatory system, rather than through the digestive system. The broad phylogenetic and metabolic diversity of this epibiotic community suggests a highly flexible and adjustable microbial consortium, adapted to the chemically contrasting environments inhabited by the shrimp. To cope with the highly fluctuating oxygen and temperature conditions of its habitat, $R$. exoculata possesses hemocyanin with a strong oxygen affinity, and has developed both molecular and behavioral responses to heat stresses. If $R$. exoculata is able to detect very dim light or chemical compounds emitted by vents, the relatively small visual and olfactory areas in the brain, along with the disproportionately enlarged higher centers, argue for a significant involvement of navigational skills using learning and place memory to orient itself within its aphotic environment. This shrimp undergoes unconventional larval development, with a primary lecithotrophic stage followed by an extended planktotrophic period, allowing a huge potential for dispersion. In light of mining licenses posing a threat for deep-sea environments, this species is a model still to be studied to better understand life in extreme deep-sea ecosystems at the global scale of an ocean.
\end{abstract}

KEY WORDS: Alvinocaridid shrimp - Chemoautotrophic symbiont - Deep-sea - Epibiosis · Holobiont $\cdot$ Hydrothermal vents $\cdot$ Mid-Atlantic Ridge $\cdot$ Rimicaris exoculata

\section{INTRODUCTION}

\subsection{Distribution of Rimicaris exoculata}

The discovery of hydrothermal vents in 1977 on ocean ridge crests off the Galapagos Islands was quickly followed by vent discoveries along the East Pacific Rise (EPR) (Lonsdale 1977, Corliss et al. 1979). Exploration of the Mid-Atlantic Ridge (MAR) began in 1985. Observed faunal assemblages on the MAR were markedly different from those described a few years earlier on the EPR, with the notable exception

\footnotetext{
*Corresponding author: magali.zbinden@upmc.fr
}

of bathymodiolin mussels. The assemblages were characterized by the absence of alvinellids and vestimentiferan tubeworms, and the presence of huge motile aggregations of shrimp (Fig. 1a) of the family Alvinocarididae, later named Rimicaris exoculata, which dominated by far the communities of the visited deep MAR vent fields (Van Dover et al. 1988, Segonzac 1992, Gebruk et al. 1997a, Desbruyères et al. 2001).

R. exoculata (Williams \& Rona 1986) has been reported on most of the known MAR sites, from $45^{\circ} 28^{\prime} \mathrm{N}$ (Moytirra) to $15^{\circ} 10^{\prime} \mathrm{S}$ (Deyin-1) (Fig. 1b, Table 1),

() The authors 2020. Open Access under Creative Commons by Attribution Licence. Use, distribution and reproduction are unrestricted. Authors and original publication must be credited. 

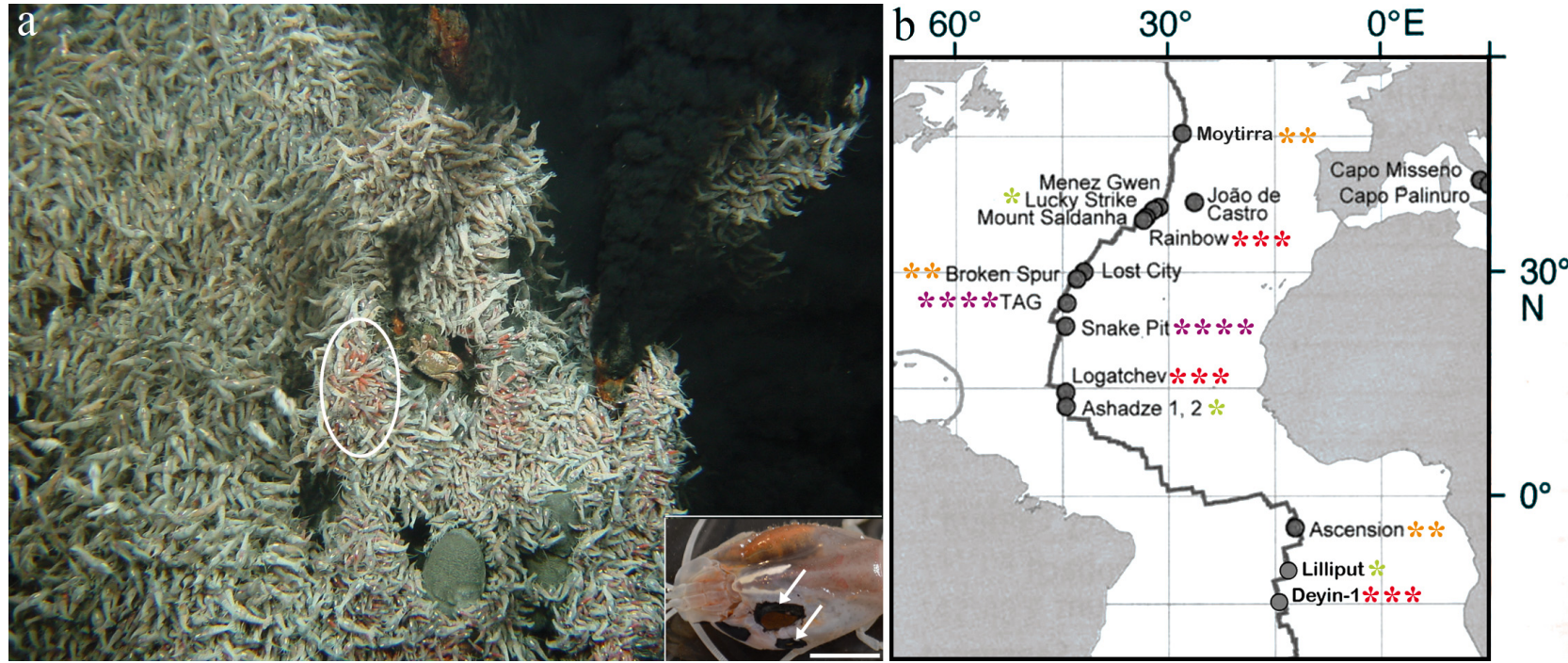

Fig. 1. (a) Rimicaris exoculata aggregation at the Trans-Atlantic Geotraverse (TAG) site (@ Exomar / Ifremer). White circle shows a patch of orange juveniles close to a fluid exit and inset shows a shrimp with traces of burns (arrows) on the branchiostegite (○ F. Pradillon). Scale bar $=1 \mathrm{~cm}$. (b) Distribution of $R$. exoculata populations along the Mid-Atlantic Ridge, with density information from the least (1 star) to the most (4 stars) colonized sites (modified from Desbruyères et al. 2006)

Table 1. Locations of Mid-Atlantic Ridge vent fields hosting Rimicaris exoculata (data from InterRidge database: http://vents-data.interridge.org/). Shrimp densities based on personal observations (M.Z. and M.A.C.B.), Desbruyères et al. (2000), Haase et al. (2009), Wheeler et al. (2013) and Dong et al. (2019). 1: very rare or not observed during the most recent cruises, 2: rare, 3: abundant, 4: very abundant. TAG: Trans-Atlantic Geotraverse

\begin{tabular}{|lccccc|}
\hline Vent field & Latitude & Longitude & $\begin{array}{c}\text { Depth } \\
(\mathrm{m})\end{array}$ & $\begin{array}{c}\text { Shrimp } \\
\text { density }\end{array}$ & Discovery \\
\hline Moytirra & $45^{\circ} 28^{\prime} \mathrm{N}$ & $27^{\circ} 51^{\prime} \mathrm{W}$ & 2095 & 2 & 2011 \\
Lucky Strike & $37^{\circ} 17^{\prime} \mathrm{N}$ & $32^{\circ} 16^{\prime} \mathrm{W}$ & 1740 & 1 & 1993 \\
Rainbow & $36^{\circ} 16^{\prime} \mathrm{N}$ & $33^{\circ} 54^{\prime} \mathrm{W}$ & 2320 & 3 & 1997 \\
Broken Spur & $29^{\circ} 10^{\prime} \mathrm{N}$ & $43^{\circ} 10^{\prime} \mathrm{W}$ & 3100 & 2 & 1993 \\
TAG & $26^{\circ} 08^{\prime} \mathrm{N}$ & $44^{\circ} 49^{\prime} \mathrm{W}$ & 3670 & 4 & 1986 \\
Snake Pit & $23^{\circ} 22^{\prime} \mathrm{N}$ & $44^{\circ} 57^{\prime} \mathrm{W}$ & 3500 & 4 & 1985 \\
Logatchev & $14^{\circ} 45^{\prime} \mathrm{N}$ & $44^{\circ} 58^{\prime} \mathrm{W}$ & 3050 & 3 & 1995 \\
Achadze & $12^{\circ} 58^{\prime} \mathrm{N}$ & $44^{\circ} 51^{\prime} \mathrm{W}$ & 4200 & 1 & 2007 \\
Ascension & $4^{\circ} 47^{\prime} \mathrm{S}$ & $12^{\circ} 22^{\prime} \mathrm{W}$ & 3050 & 2 & 2005 \\
Lilliput & $9^{\circ} 33^{\prime} \mathrm{S}$ & $13^{\circ} 10^{\prime} \mathrm{W}$ & 1500 & 1 & 2005 \\
Deyin-1 & $15^{\circ} 10^{\prime} \mathrm{S}$ & $13^{\circ} 21^{\prime} \mathrm{W}$ & 2850 & 3 & 2011 \\
\hline
\end{tabular}

with the exception of the shallowest sites: Menez Gwen (850 m depth), Lilliput (1500 m depth) and Lucky Strike (1700 $\mathrm{m}$ depth), where no or only very few specimens have been observed (Gebruk et al. 2000, Pond et al. 2000a,b, Dong et al. 2019).

\subsection{Habitat}

$R$. exoculata, the most extensively studied hydrothermal shrimp species to date, occurs on active chimney walls, in astonishingly dense aggregations of up to 3000 ind. $\mathrm{m}^{-2}$ (Fig. 1a), packed side by side and piled on 2 or more layers (Van Dover et al. 1988, Segonzac 1992, Copley et al. 1997, Gebruk et al. 1997a, 2000). Adults of $R$. exoculata are generally found crawling on the substratum (Rona et al. 1986, Segonzac et al. 1993) and maintain high levels of activity on walls of active black smokers (Van Dover et al. 1988). When displaced from the substratum, the shrimp immediately seek to re-establish themselves near the source of hydrothermal fluid (Van Dover et al. 1988, Renninger et al. 1995), resulting in a teeming swarm oriented against the current of vent fluids (Copley et al. 1997). These dense aggregations were proposed to form in response to physical constraints such as the restricted availability of substratum exposed to hydrothermal fluids (Polz et al. 1998, Gebruk et al. 2000) or the selection of an appropriate thermal niche (Ravaux et al. 2009). However, Ravaux et al. (2019) observed shrimp aggregations in pressurized aquaria, in a homogeneous environment and in the absence of any environmental cues. They thus suggested for the first time that $R$. exoculata aggregations may form not only as a result of the independent attraction of individuals to a resource, but 
could also be the result of some social behavior that provides benefits.

$R$. exoculata lives within steep thermal and chemical gradients, where hot, reduced hydrothermal fluid mixes turbulently with cold, oxygenated seawater (Schmidt et al. 2008b). The thermal environment within the aggregations has been well documented, with reported temperatures ranging from 2.8 to $32^{\circ} \mathrm{C}$ (Van Dover et al. 1988, Segonzac et al. 1993, Desbruyères et al. 2001, Geret et al. 2002, Zbinden et al. 2004, Schmidt et al. 2008a), although measurements taken within a few centimeters of the shrimp aggregations (Zbinden et al. 2004, Schmidt et al. 2008a) do not exceed $18^{\circ} \mathrm{C}$. Many shrimp were reported with burns on the cuticle, pereopods, pleopods or antennae (Van Dover et al. 1988, Gebruk et al. 1993, Segonzac et al. 1993, Gebruk et al. 2000; see inset in Fig. 1), indicating that they likely sometimes encounter much higher temperature peaks. On the other hand, occasionally few shrimp occur, rather motionless, scattered at the periphery of a community, exposed to temperatures just above that of ambient seawater $\left(2.4^{\circ} \mathrm{C}\right)$ (Gebruk et al. 1993, Segonzac et al. 1993).

$R$. exoculata colonizes sites along the MAR with chemically contrasting environments. Most active hydrothermal sites known to date are basaltic, i.e. based on underlying rocks of a basaltic nature. Waterrock interactions at basalt-hosted vents (such as the Trans-Atlantic Geotraverse [TAG], Broken Spur or Snake Pit) release end-member fluids enriched in hydrogen sulfide $\left(\mathrm{H}_{2} \mathrm{~S}\right)$, but are relatively depleted in hydrogen $\left(\mathrm{H}_{2}\right)$ and methane $\left(\mathrm{CH}_{4}\right)$ (Table 2). On the other hand, the hydrothermal circulation at ultramafic sites (Rainbow, Logatchev, Ashadze) is the result of interaction between seawater and mantle rocks outcropping at the seafloor. The end-member fluid composition of those vents departs from that of the typical basaltic end-member, and is relatively depleted in $\mathrm{H}_{2} \mathrm{~S}$ and enriched in $\mathrm{H}_{2}$, ferrous iron (FeII) (notably at the Rainbow site) and $\mathrm{CH}_{4}$, due to serpentinization processes (Charlou et al. 2002, 2010, Dou- ville et al. 2002). Thus, $R$. exoculata encounters contrasting chemical habitats at the different sites. The chemical environment within the shrimp aggregations is less documented than the thermal environment. In situ measurements of temperature, $\mathrm{pH}$, ferrous iron and sulfide concentrations within the aggregations reflect the moderate contribution of hydrothermal fluid in the mixing with seawater (Zbinden et al. 2004). Analyses at the Rainbow site revealed nearneutral $\mathrm{pH}$ (6.3-8), high levels of ferrous iron (0.13$265 \mu \mathrm{M})$, moderate methane levels $(21 \mu \mathrm{M})$ and low levels of sulfide (0.4-22 $\mu \mathrm{M}$ ) (Geret et al. 2002, Zbinden et al. 2004, Schmidt et al. 2009). Little or no data are available within the aggregations for other hydrothermal sites (see Schmidt et al. 2008a,b for data from the TAG site, showing lower methane and ferrous iron concentrations).

$R$. exoculata abundance varies among sites (see Fig. 1b), from isolated individuals at Achadzé (Fouquet et al. 2008) to aggregations of hundreds to thousands of individuals almost entirely covering active chimney walls at TAG (Williams \& Rona 1986; Fig. 1a). However, the parameters influencing the distribution of this shrimp remain unknown. The importance of flow rate, chemical composition and/or temperature of the hydrothermal fluid, or even duration of activity of the site, remains to be determined (Schmidt et al. 2008b).

\subsection{Brief morphological description}

Following is a brief description of specific morphological characteristics of the species, according to Williams \& Rona (1986), Segonzac et al. (1993) and Komai \& Segonzac (2008) (Fig. 2). The size (total length measured from the anterior tip of the cephalothorax to the end of the telson) ranges from 31.3$50.2 \mathrm{~mm}$ for males, 42.3-57.4 mm for females and 23$47.4 \mathrm{~mm}$ for juveniles. The rostrum is strongly reduced. The antennular and antennal peduncles are hyper-

Table 2. Concentration of the main electron donors in the seawater (SW) and in the end-member fluid of different hydrothermal vent sites colonized by Rimicaris exoculata populations (data from Desbruyères et al. 2000, Douville et al. 2002, Charlou et al. 2002, 2010, Demina et al. 2013). TAG: Trans-Atlantic Geotraverse, -: no data available

\begin{tabular}{|lccccccc|}
\hline & SW & Rainbow & Broken Spur & TAG & Snake Pit & Logatchev & Achadze \\
\hline Type of host rock & & Ultramafic & Basaltic & Basaltic & Basaltic & Ultramafic & Ultramafic \\
$\mathrm{pH}$ & 7.8 & $2.8-3.1$ & $2.9-3.2$ & $2.5-3.4$ & $3.7-3.9$ & $3.3-3.9$ & 3.1 \\
$\mathrm{H}_{2} \mathrm{~S}(\mathrm{mM})$ & 0 & $1.2-1.4$ & $8.5-11$ & $2.5-6.7$ & 6.7 & $1.1-1.4$ & 1 \\
$\mathrm{CH}_{4}(\mathrm{mM})$ & 0.0003 & $1.6-2.5$ & $0.065-0.13$ & $0.124-0.147$ & $0.046-0.062$ & $2-2.6$ & $0.5-1.2$ \\
$\mathrm{H}_{2}(\mathrm{mM})$ & 0.0004 & $13-16$ & $0.43-1.03$ & $0.15-0.37$ & - & $9-12.5$ & $8-19$ \\
$\mathrm{Fe}(\mu \mathrm{M})$ & $<0.001$ & $17700-24050$ & $1680-2160$ & $1640-5450$ & 2400 & $1825-2500$ & 9300 \\
\hline
\end{tabular}


a
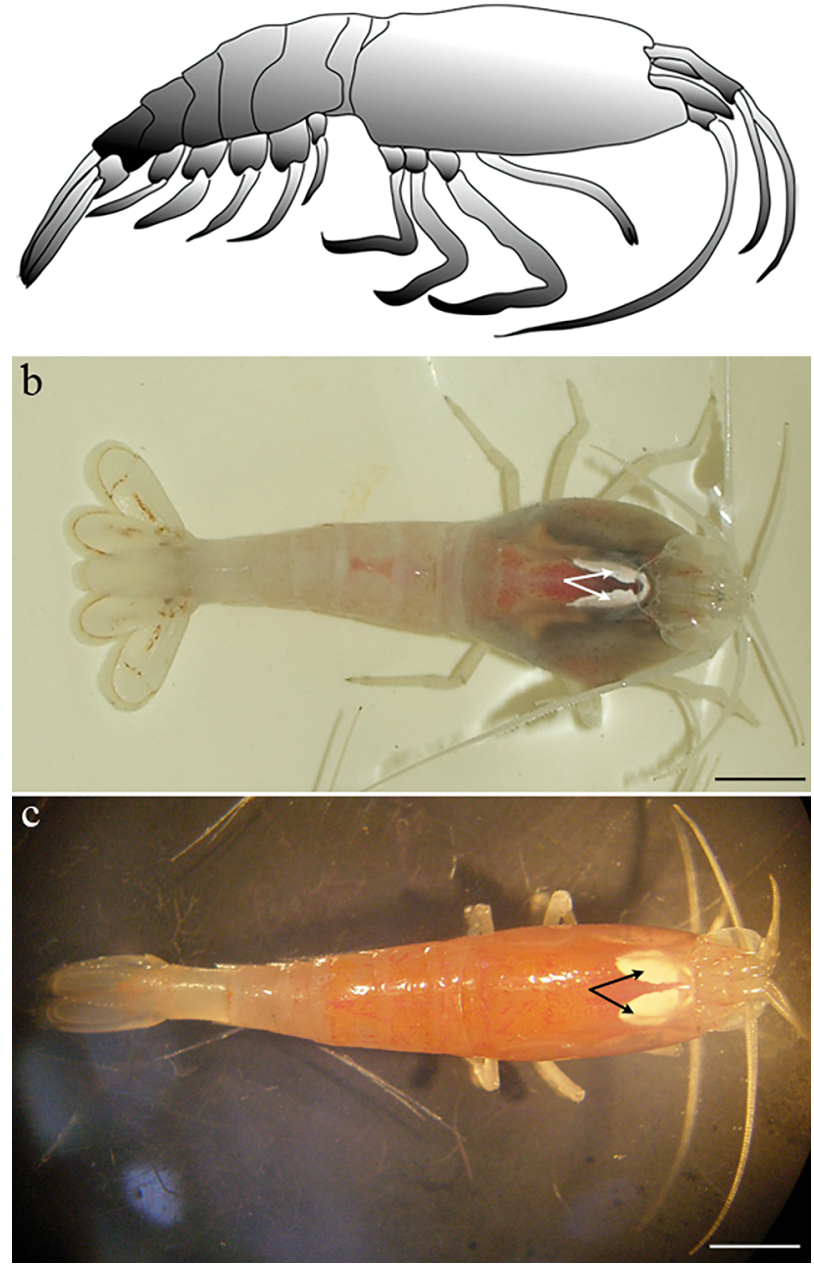

Fig. 2. (a) Lateral view of Rimicaris exoculata. (b) Dorsal view of an adult showing the strongly inflated cephalothorax. (c) Dorsal view of a juvenile showing the bright orange coloration and the narrow cephalothorax. Arrows in panels $\mathrm{b}$ and $\mathrm{c}$ show the dorsal eye. Scale bars $=1 \mathrm{~cm}(\mathrm{~b}), 0.2 \mathrm{~cm}(\mathrm{c})$

trophied. The cephalothorax is dorsoventrally compressed, distinctly broader than the pleon, with strongly inflated branchial regions. The carapace extends forward both ventrally and encloses cephalic, but also anterior thoracic appendages up to the second pair of pereiopods, in an almost closed 'prebranchial' chamber. The structure of the mouthparts is particularly modified: exopodites of the second maxilla (hereafter called scaphognathites) and of the first maxillipeds (hereafter called exopodites) are enormously expanded anteriorly, occupying twothirds of the prebranchial chamber. They are entirely covered on both sides with long and numerous bacteriophore setae (Fig. 3). The mandibles have regressed. The first 2 pereiopods are relatively small and probably cannot extend out of the branchial chamber. The strongly modified ocular region is characterized by transverse ocular plates, with no eye-stalks (see Section 3.2 for further description).

\subsection{Classification}

The generic name Rimicaris derives from the Latin 'rima,' meaning rift or fissure, with reference to the MAR, and from the Greek 'karis,' meaning shrimp. The specific epithet 'exoculata' derives from the Latin term 'exoculo,' meaning deprived of eyes, with reference to the highly modified, non-image-forming, eyes (Williams \& Rona 1986).

The genus Rimicaris was originally established (in the family Bresiliidae) for 2 species discovered from the hydrothermal vent field TAG on the MAR: $R$. exoculata (Williams \& Rona 1986) and $R$. chacei (Williams \& Rona 1986). The former was designated as the type species of the genus. The genus Rimicaris was later assigned to the family Alvinocarididae (Christoffersen 1986, Segonzac et al. 1993, Komai \& Segonzac 2003). A new subfamily (Rimicaridinae) comprising the genus Rimicaris was created in 2015 (Vereshchaka et al. 2015).

Two 'small orange' species, namely $R$. aurantiaca (Martin et al. 1997), described from the Snake Pit site, and Iorania concordia (Vereshchaka 1996), described from the TAG site, were subsequently recognized to be $R$. exoculata juveniles. This initial taxonomic confusion was due to important morphological differences between juvenile and adult $R$. exoculata (Martin \& Haney 2005). Coloration between adults of $R$. exoculata and the small bright orange shrimp were very different. The slightly inflated branchiostegites and oval ocular plates of the small orange shrimp contrasted with the highly inflated branchiostegites and wing-shaped ocular plates of $R$. exoculata adults (Vereshchaka 1996, Nuckley et al. 1996, Shank et al. 1998). However, the absence of brooding females and mature males with developed appendix interna in samples of the small orange shrimp, as well as the small size of these orange shrimp vs. adult $R$. exoculata raised some doubts. Allozymes and mitochondrial DNA sequences of samples from the Broken Spur, TAG and Snake Pit sites confirmed that these 2 small orange shrimp 'species' were indeed $R$. exoculata juveniles (Segonzac et al. 1993, Creasey et al. 1996, Shank et al. 1998).

The genus Rimicaris currently contains 10 species. $R$. exoculata, $R$. kairei (described from the hydrothermal vent field 'Kairei' on the Central Indian Ridge, Watabe \& Hashimoto 2002) and R. hybisae 

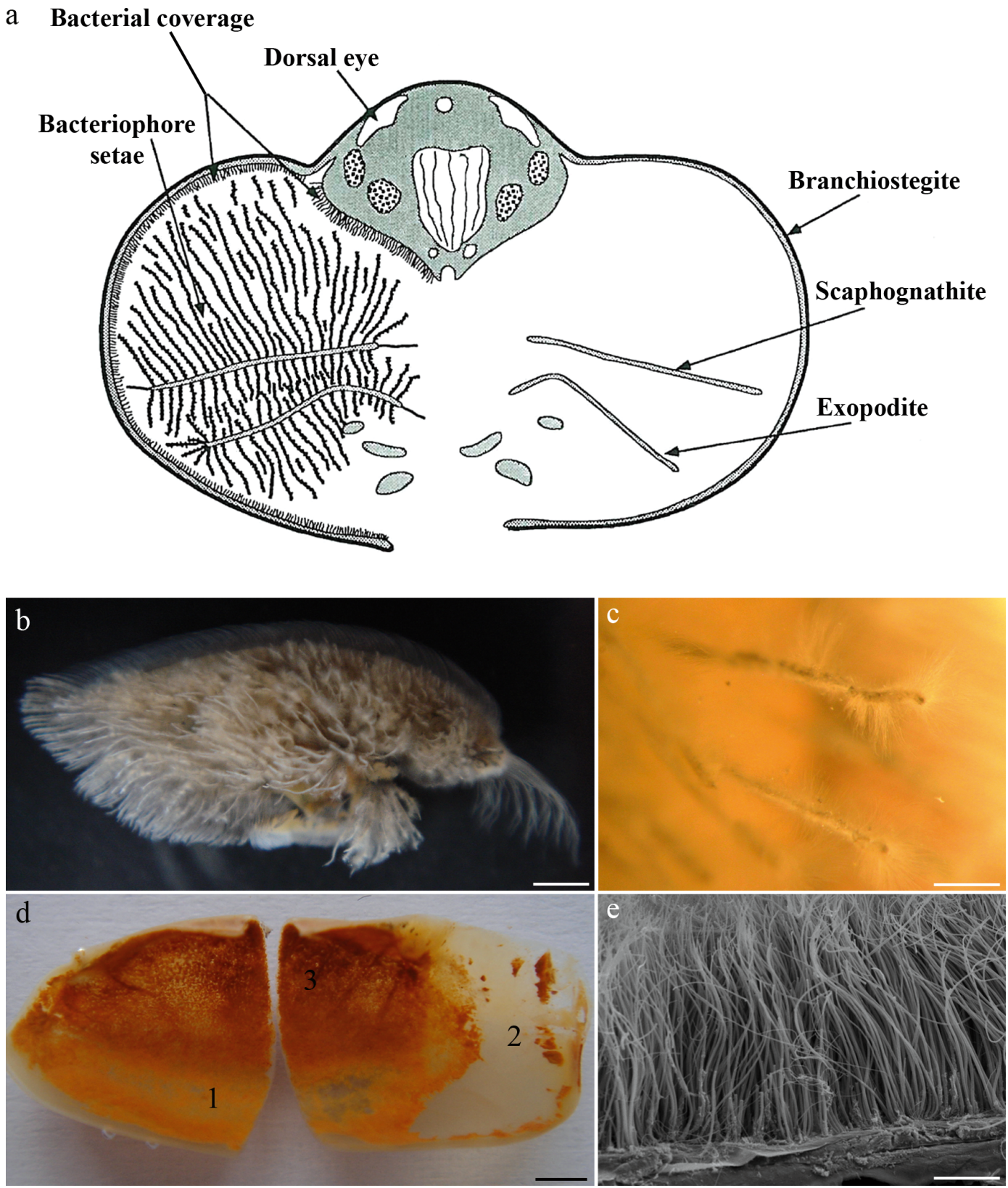

Fig. 3. Rimicaris exoculata epibiotic bacteria of the branchial chamber. (a) Schematic cross-section of the cephalothorax showing the localization of the bacteria (inner side of the branchiostegite, bacteriophore setae of the scaphognathites and expopodites) (modified from Segonzac et al. 1993). (b) Scaphognathite with bacteriophore setae. (c) Close-up of a seta covered by filamentous bacteria. (d) Inner side of the banchiostegite covered by orange iron oxides (1: lower pre-branchial chamber, 2: true branchial chamber, 3: upper pre-branchial chamber, housing the main ectosymbiotic bacterial community) (photo by P. Compère). (e) Scanning electron microscopy close-up of the mat of filamentous bacteria in the pre-branchial chamber ( 3 in panel d). Scale bars $=2 \mathrm{~mm}(\mathrm{~b}, \mathrm{~d}), 100 \mu \mathrm{m}(\mathrm{c}, \mathrm{e})$

(described from hydrothermal vent fields on the MidCayman Spreading Centre, Nye et al. 2012) were the 3 initially recognized Rimicaris species. Six species previously assigned to the genus Chorocaris were later synonymized with Rimicaris in 2015 (Vereshchaka et al. 2015), following previous recommendations (Creasey et al. 1996, Shank et al. 1999, Teixeira et al. 2013, Komai \& Tsuchida 2015): R. chacei (Williams \& Rona 1986), R. vandoverae (Martin \& Hessler 1990), R. paulexa (Martin \& Shank 2005), $R$. susannae (Komai et al. 2007), R. parva (Komai \& Tsuchida 2015) and $R$. variabilis (Komai \& Tsuchida 2015). Finally, Komai \& Giguère (2019) described a new Rimicaris species ( $R$. falkorae) from the Mariana 
Back Arc Spreading Center. Within the current Rimicaris genus, $R$. exoculata, $R$. kairei and $R$. hybisae present an enlarged branchial chamber, which houses a dense epibiotic bacterial community. In the 7 other species, the scaphognathites are moderately broad and devoid of bacteriophore setae (except for $R$. vandoverae and $R$. chacei). Until now, no symbiotic association has been described for these species, except for $R$. chacei, which harbors a symbiotic community both in its gut and in its branchial chamber, although less developed than in $R$. exoculata (Casanova et al. 1993, Gebruk et al. 2000, Apremont et al. 2018).

\section{DOUBLE SYMBIOSIS}

Two microbial epibiotic communities are associated with Rimicaris exoculata: the most prominent (and most studied) one is located in the branchial chamber, the other in the gut.

\subsection{Branchial chamber symbionts}

\subsubsection{Bacterial localization}

Bacteria colonize almost all of the available surfaces of the branchial chamber (Fig. 3a), with the notable exceptions of the gills and inner side of the branchiostegites facing them (Zbinden et al. 2004). Bacteria are mostly present on the bacteriophore setae of the dorsal and ventral sides of the hypertrophied exopodites and scaphognathites (Fig. 3b,c), as well as on the internal tegument of the carapace (hereafter called branchiostegites) (Fig. 3d,e) (Casanova et al. 1993, Segonzac et al. 1993). Using oligonucleotide slot-blot hybridization, Polz \& Cavanaugh (1995) estimated that an average shrimp would carry $8.5 \times 10^{6}$ bacteria in its branchial chamber, which would correspond to $(2-4) \times 10^{11}$ bacteria $\mathrm{m}^{-2}$ in the aggregations.

Investigation of bacteria (Fig. 3d) by photonic and scanning electron microscopy (SEM) (Fig. 3e) on the inner side of the branchiostegite revealed 3 distinct compartments in the branchial chamber: (1) the lower pre-branchial chamber, with only a thin bacterial coverage; (2) the 'true' branchial chamber, containing the gills and completely devoid of bacteria; and (3) the upper pre-branchial chamber, housing the main ectosymbiotic bacterial community. The limit between the upper and lower pre-branchial chamber corresponds to the position of the exopodites, the scaphognathites being entirely enclosed in the upper pre-branchial chamber (Zbinden et al. 2004). The water current, generated by the beating of the scaphognathites, enters ventrally, passes from the lower pre-branchial chamber (first compartment), to the gills (second compartment), and then through the upper pre-branchial chamber containing the main epibiont community (third compartment) (Casanova et al. 1993, Segonzac et al. 1993, Zbinden et al. 2004).

\subsubsection{Trophic symbiosis}

In deep-sea hydrothermal ecosystems, deprived of photosynthetic activity, chemoautotrophic bacteria fueled by hydrothermal fluid reduce compounds (mainly sulfur and methane, Nelson \& Fisher 1995) to sustain a complex and dense food web. Here, the primary consumers gain their energy directly from these primary producers through direct consumption or through the establishment of symbioses. The huge densities of $R$. exoculata on the MAR, and their dominance at many sites, rapidly raised questions on how these populations were sustained (Van Dover et al. 1988). Furthermore, these shrimp cluster close to the mixing zone between the hot fluids and seawater, displaying intense activity, which is unusual for deepsea organisms (Segonzac 1992).

The first investigations on the feeding biology of $R$. exoculata led Van Dover et al. (1988) to propose that these shrimp were normal heterotrophs, grazing on free-living microorganisms colonizing the black smoker chimney walls. This conclusion came from: (1) their results of lipopolysaccharide assays revealing large amounts of bacterial cell-wall material in the stomach content, along with the fact that the gut was filled with sulfide particles; (2) their data of $\delta^{15} \mathrm{~N}$ $\left(+7.5 \%\right.$ o) and $\delta^{34} \mathrm{~S}(+9.7 \%)$ isotopic ratios; and (3) the fact that they were unable to detect any autotrophy activity (i.e. ribulose-1,5-bisphosphate carboxylase activity) in the studied tissues (gut, hepatopancreas, gonads, abdominal muscles). These authors, looking only for chemoautotrophic endosymbiotic bacteria, nevertheless acknowledged that they may have missed the correct host tissues. They also reported the occurrence of a dense coating of filamentous microorganisms on the setae of the scaphognathites and exopodites, which they proposed to constitute a second nutritional source.

It rapidly became clear that, if shrimp occupy a substratum directly exposed to the hydrothermal fluid flow, it would enable chemosynthetic primary production by the epibiotic chemosynthetic bacterial community hosted in their branchial chamber (Gebruk et al. 1993, Polz \& Cavanaugh 1995). Indeed, some au- 
thors argued that the amount of bacteria present on chimney walls was not enough to support the shrimp population. They rather proposed an alternative hypothesis to that of Van Dover et al. (1988), suggesting that $R$. exoculata gained most of its carbon from the epibiotic bacteria living within its carapace, by scraping and grazing on them (Casanova et al. 1993, Gebruk et al. 1993, Wirsen et al. 1993, Polz et al. 1998, Rieley et al. 1999). The morphology of the 2 pairs of chelipeds, which are relatively small, suggests that they probably cannot extend out of the branchial chamber to graze the chimney walls. By contrast, they are able to reach and clean the surfaces of all appendages within the branchial chamber, as well as the internal walls of the carapace, and then carry the scraped particles to the mouth (Van Dover et al. 1988).

The highly specialized morphological features of $R$. exoculata (hypertrophied branchial chamber and mouthparts, bacteriophore setae, Fig. 3) suggest an efficient bacterial culture in the shrimp pre-branchial chamber and argue for a trophic symbiosis (Gebruk et al. 1993). A number of lines of evidence converge towards the present consensus, i.e. that the epibionts are the major source of carbon (80\%, according to a calculation by Polz et al. 1998): (1) close $\delta^{13} \mathrm{C}$ values of the saturated and monounsaturated fatty acids isolated from the muscle tissues of $R$. exoculata $(-13 \%)$ and the epibionts $(-12 \%)$, (2) very high level of polyunsaturated (n-7) and (n-4) fatty acids, both in the epibionts and in $R$. exoculata tissues (Pond et al. 1997a, 2000a,b, Allen-Copley et al. 1998, Rieley et al. 1999). Many studies reached similar conclusions considering the close $\delta^{13} \mathrm{C}$ signature between the epibiotic bacteria ( -9.3 to $-12.4 \%$; Polz et al. 1998, Gebruk et al. 2000) and $R$. exoculata tissues (-10 to $-12.5 \%$, Van Dover et al. 1988, Gebruk et al. 1997b, 2000, Pond et al. 1997a, Polz et al. 1998, Vereshchaka et al. 2000).

Several years later, a third hypothesis argued for a trans-epidermal transfer of dissolved organic matter from the epibiotic bacteria through the branchiostegite cuticle (Casanova et al. 1993, Zbinden et al. 2004, Corbari et al. 2008a). Some authors (Gebruk et al. 2000) first rejected this hypothesis, on the basis of previous studies arguing that transport of dissolved organic matter across the chitinous exoskeleton in crustaceans is unlikely (Stephens 1988). This hypothesis is nevertheless supported by several points: (1) the thinness of the cuticle (as low as $0.5 \mu \mathrm{m}$ ) and the important hemolymphatic lacunas underlying it; (2) the numerous membrane infoldings and mitochondria in branchiostegite epithelium beneath the bacteria (Martinez et al. 2005), suggesting an important epidermal transport activity; and (3) the absence of any scraped areas on the inner side of branchiostegites or on scaphognathites despite a considerable number of observations (Zbinden et al. 2004, Corbari et al. 2008a). Although supporting the hypothesis that the shrimp grazed off their epibionts, Polz et al. (1998) noticed that only slightly more than $20 \%$ of the rRNA detected in the gut corresponds to that of the epibionts. In order to test the trans-tegumental hypothesis, Ponsard et al. (2013) performed in vivo shrimp incubations in a pressurized aquarium with isotope-labeled inorganic carbon $\left(\mathrm{NaH}^{13} \mathrm{CO}_{3}\right.$ and $\mathrm{NaH}^{14} \mathrm{CO}_{3}$ ), to trace carbon assimilation by the epibionts and shrimp tissues. The high ${ }^{13} \mathrm{C}$ and ${ }^{14} \mathrm{C}$ incorporation in the bacterial biofilms of scaphognathites and branchiostegites (Fig. 4a) proves that they are indeed chemoautotrophs. The higher incorporation rates in the presence of iron or thiosulfate indicates that both sulfide and iron oxidation metabolism occurs among the epibionts. Among the shrimp tissues analyzed (outer branchiostegite [i.e. the branchiostegite epithelium and its outer cuticle], gills, hepatopancreas, digestive tract, abdominal muscles), the highest incorporation rate was measured in the outer branchiostegite $\left(2.7 \mu \mathrm{mol} \mathrm{C} \mathrm{inc}_{\mathrm{in}} \mathrm{gC}^{-1} \mathrm{~h}^{-1}\right)$ and to a lesser extent the gills $\left(0.2 \mu \mathrm{mol} \mathrm{C}_{\mathrm{inc}} \mathrm{gC}^{-1} \mathrm{~h}^{-1}\right)$. The rates recorded for the internal tissues of all shrimp (muscles: 0.01; digestive tract: 0.04 ; hepatopancreas: $0.01 \mu \mathrm{mol} \mathrm{C}$ inc $\mathrm{gC}^{-1} \mathrm{~h}^{-1}$ ) were low to very low. These results showed that chemosynthetic bacterial organic carbon passes to the host through a direct absorption across the branchial chamber integument (Fig. 4b-d), rather than via the digestive tract. They thus provide the first direct evidence of a true symbiotic trophic interaction between the host and its epibiotic bacteria.

\subsubsection{Bacterial morphological diversity}

Using SEM, the first observations of the epibionts revealed 3 bacterial morphotypes: 2 filamentous types (one thin: $0.2-1 \mu \mathrm{m}$; one thick: $1-3 \mu \mathrm{m}$ in diameter, both up to $250 \mu \mathrm{m}$ in length, Fig. 5a) and 1 rodshaped type $(0.5 \times 1.5 \mu \mathrm{m}$, Fig. 5e) (Casanova et al. 1993, Gebruk et al. 1993, Segonzac et al. 1993, Zbinden et al. 2004).

Additional observations with transmission electron microscopy (TEM) on Rainbow samples refined these data, leading to the identification of 6 different morphotypes (Zbinden et al. 2008). Two sub-types of rods were distinguished based on size and intracellular aspect: (1) short and thick rods $(0.6 \times 1.25 \mu \mathrm{m})$, with a dense dark intracellular content and (2) longer and 

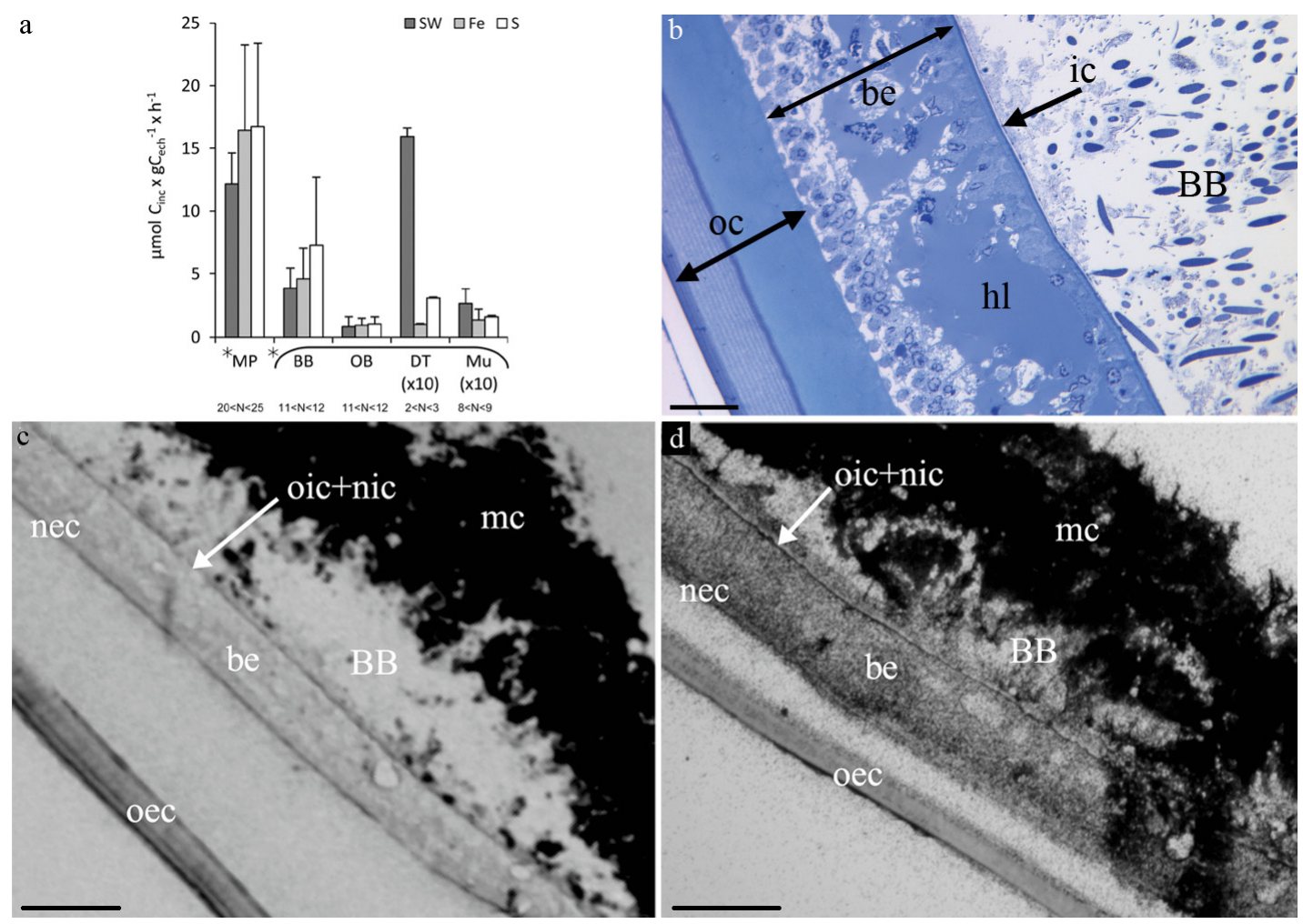

Fig. 4. Incorporation of inorganic carbon into bacterial mats and shrimp tissues. (a) ${ }^{13} \mathrm{C}$ fixation for specimens incubated for $10 \mathrm{~h}$ in $\mathrm{NaH}^{13} \mathrm{CO}_{3}$ in pure seawater (SW; dark grey), supplemented with reduced iron (Fe, light grey) or thiosulfate (S, white) (from Ponsard et al. 2013). Stars indicate significant differences between groups of tissues; ' $\times 10$ ' indicates tissues for which the values were multiplied by 10 for graphical presentation, ' $\mathrm{N}^{\prime}$ indicates the number of samples for each data bar. MP: mouth parts; BB: bacterial biofilm; OB: outer branchiostegite (= shrimp branchiostegite tissue); DT: digestive tract; Mu: muscles. (b) Semi-thin cross-section (toluidine blue stained) of the branchiostegite, showing the inner (ic) and outer cuticle (oc) and the bacterial biofilm (BB) growing on the inner side, close to the hemolymphatic lacunas (hl) of the branchiostegite epithelium (be). (c,d) Autoradiography of the branchiostegite of a specimen incubated with ${ }^{14} \mathrm{C}$-acetate: (c) after only $3 \mathrm{~d}$ and (d) after $11 \mathrm{~d}$ of exposure (from Ponsard et al. 2013). oec: old external cuticle; oic: old internal cuticle; nic: new internal cuticle; nec: new external cuticle; mc: mineral crust. Scale bars $=50 \mu \mathrm{m}(\mathrm{b}), 100 \mu \mathrm{m}(\mathrm{c}, \mathrm{d})$

thinner rods $(0.3 \times 3 \mu \mathrm{m})$, with a light intracellular content. Two sub-types of thin filaments were also described based on their cell morphology and intracellular aspect: (1) thin filaments with rectangular cells, no marked narrowing between 2 adjacent cells and a homogeneous and dense content and (2) thin filaments with ovoid cells, with a marked narrowing between 2 adjacent cells, a more heterogeneous intracellular content and occurrence of intracellular electron-dense granules (Fig. 5c). Finally, in addition to the previously described thick filaments, these authors reported the occurrence of bacteria with stacks of intracytoplasmic membranes typical of type I methanotrophs, bringing the diversity to 6 morphotypes (Fig. 5b).

Intracellular granules were observed in the thin filaments (but not in the other morphotypes). Energy dispersive $\mathrm{x}$-ray microanalysis revealed 2 types of granules: one containing phosphorus and iron, prob- ably as iron polyphosphate, and the other containing only sulfur (Zbinden et al. 2008). Gebruk et al. (1993) also reported the occurrence of granules of elemental sulfur in the filamentous bacteria of $R$. exoculata. Shrimp maintenance in a pressurized aquarium led to the emptying of most of the granules, thus suggesting a storage role (Zbinden et al. 2008).

\subsubsection{Bacterial phylogenetic diversity}

Hydrothermal endosymbioses were initially thought to rely on a limited number of symbionts (for example, only 1 symbiont, a sulfur-oxidizing Gammaproteobacteria species, was identified in Riftia pachyptila, Calyptogena magnifica and Bathymodiolus thermophilus, Distel et al. 1988). However, further studies showed a higher diversity of closely related bacterial lineages co-occurring in a single host (see Duperron 
Fig. 5. Diversity of branchial chamber bacterial epibionts. (a) Scanning electron microscopy (SEM) view of the thick and thin filamentous bacteria on the inner face of the branchiostegite. (b) Transmission electron microscopy (TEM) view of methanotrophic bacteria characterized by stacks of intracytoplasmic membranes. (c) TEM view of intracellular granules in the thin filaments. (d) Fluorescence in situ hybridization view of a scaphognathite seta showing Campylobacteria thick and thin filaments (green) and Gammaproteobacteria thin filaments (red). (e) SEM view of a monolayer of prostrate and erect rod-shaped bacteria. Scale bars = $10 \mu \mathrm{m}(\mathrm{a}, \mathrm{d}, \mathrm{e}), 0.5 \mu \mathrm{m}(\mathrm{b}, \mathrm{c})$
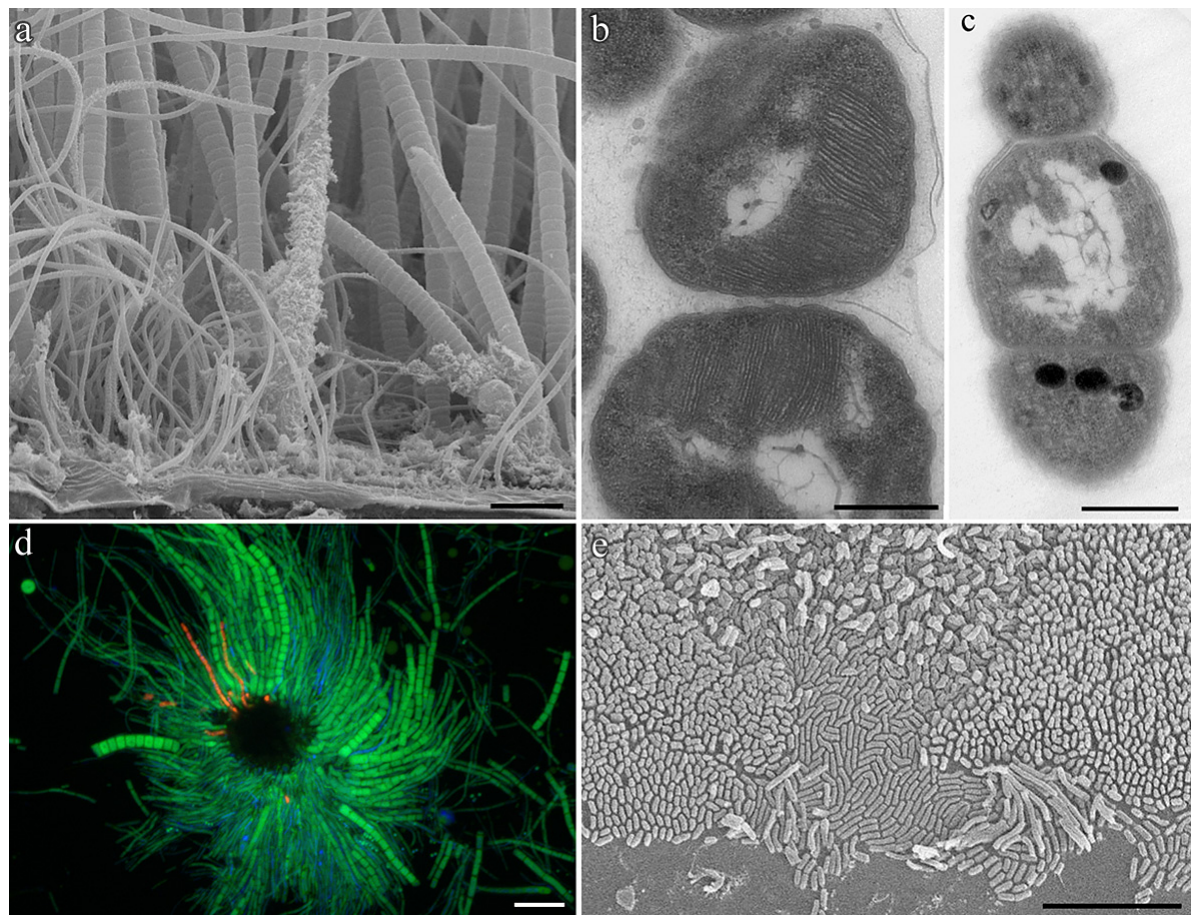

et al. 2008, Ansorge et al. 2019). Likewise, the first phylogenetic study (Polz \& Cavanaugh 1995) showed that all $R$. exoculata epibionts belonged to a single bacterial lineage of Campylobacteria (previously assigned to Epsilonproteobacteria; Waite et al. 2017, 2018), which is no longer supported. The high morphological diversity observed among the $R$. exoculata symbiotic community (see references above) rather argues for a higher phylogenetic diversity, a hypothesis proposed by Polz \& Cavanaugh (1995). Advances in sequencing technologies helped to refine the initial data and showed a much greater diversity. Two dominant groups were identified: Campylobacteria (up to $90 \%$ based on investigated specimens) and Gammaproteobacteria (10-30\%). Alpha-, Beta-, Delta- and Zetaproteobacteria, as well as Bacteroidetes, Flavobacteria, Bacilli, Clostridia and even some Aquificae were also reported at lower abundance (Zbinden et al. 2008, Petersen et al. 2010, Hügler et al. 2011, Guri et al. 2012, Jan et al. 2014, Jiang et al. 2020).

Fluorescent in situ hybridization (FISH) observations allowed intersecting data of morphology and molecular biology, confirming the predominance of Campylobacteria with thick and thin filamentous morphologies and Gammaproteobacteria related to some thin filamentous morphologies and rods (Fig. 5d, Hügler et al. 2011, Guri et al. 2012, Liu et al. 2019). Type I methanotrophic Gammaproteobacteria resemble circular 'donuts' in FISH (Guri et al. 2012). Zetaproteobacteria appear as rod-shaped curved bacteria, fixed on the host tegument (Jan et al. 2014). Some Deltatproteobacteria also appear as rods, close to the shrimp tegument (Hügler et al. 2011, Liu et al. 2019, Jiang et al. 2020).

\subsubsection{Bacterial metabolic diversity}

The single phylotype initially described was inferred to be a sulfur-oxidizer, because of its morphological resemblance to Thiothrix (Wirsen et al. 1993) and the occurrence of sulfur granules within the cells (Gebruk et al. 1993). Several authors later suggested that, at hydrothermal vents, a number of other reduced inorganic compounds could be used as electron donors by chemoautotrophic bacteria, such as hydrogen, ammonia, and nitrite, and heavy metals such as iron or manganese (Jannash \& Wirsen 1979, Segonzac et al. 1993). Attempts to cultivate these symbionts (and beyond, all other currently known symbionts) have remained unsuccessful to date. Potential metabolism can thus only be inferred from in vivo experiments on animals or fresh bacteria (Fisher et al. 1989, Zbinden et al. 2008, Scott et al. 2012, Ponsard et al. 2013), occurrence of specific genes, transcripts or other indirect assumptions, as described below.

2.1.5.1. Carbon fixation. Chemoautotrophic metabolism relies on bacterial oxidation of reduced compounds available in fluids, mostly $\mathrm{H}_{2} \mathrm{~S}, \mathrm{CH}_{4}$, Fe and $\mathrm{H}_{2}$. Along the MAR, the fluids emitted at the different 
sites colonized by $R$. exoculata show distinct chemical compositions, as summarized in Table 2 (see Section 1.2 for explanations).

Chemoautotrophy of the branchial chamber bacterial community was established early by reports of both ${ }^{14} \mathrm{C}$-labeled bicarbonate incorporation and high ribulose-1,5-bisphosphate carboxylase/oxygenase (Rubisco) activity in the bacteria covering the shrimp mouthparts and carapace (Wirsen et al. 1993, Polz et al. 1998). Moreover, in vivo experiments demonstrated autotrophic capabilities of Campylobacteria and Gammaproteobacteria lineage morphotypes (Ponsard et al. 2013). According to molecular approaches (single-gene PCR amplification to metagenomic studies), 3 carbon fixation pathways co-occur in the $R$. exoculata epibiotic community. All chemoautotrophic Campylobacteria investigated to date (Campbell \& Cary 2004, Hügler et al. 2005, 2011, Jan et al. 2014) use the reductive tricarboxylic acid (rTCA) cycle, highlighted by gene detection of its key enzyme: the ATP-dependent citrate lyase (Hügler et al. 2011). In the metagenome of $R$. exoculata mouthparts and branchiostegites, the rTCA complete set of genes was recovered (Jan et al. 2014). The second most important pathway is the Calvin-Benson-Bassham (CBB) cycle, highlighted by gene detection of its key enzyme: Rubisco. Gammaproteobacteria (Hügler et al. 2011, Beinart et al. 2012) typically use the CBB cycle. All of the $\mathrm{CBB}$ cycle genes were identified in the metagenome from $R$. exoculata mouthparts (Jan et al. 2014). Two notable exceptions to this usual pattern of CBB/ Gammaproteobacteria and rTCA/Campylobacteria are: (1) the Riftia pachyptila gammaproteobacterial endosymbiont Endoriftia persephone (as well as other siboglinid endosymbionts) in which both carbon fixation pathways co-occur (Markert et al. 2007, Yang et al. 2020), and (2) campylobacterial epibionts of deep-sea mussels which use the CBB cyle for carbon fixation (Assié et al. 2020). Genes for the CBB cycle were also retrieved in $R$. exoculata-associated Zetaproteobacteria (Jan et al. 2014). Recently, a third carbon fixation pathway was highlighted among epibionts of the $R$. exoculata branchial chamber: the Wood-Ljungdahl pathway (Jiang et al. 2020), for which nearly all genes required were highlighted in the deltaproteobacterial epibiont 'Candidatus Desulfobulbus rimicarensis' metagenome and transcriptome (Jiang et al. 2020).

Incorporation of radio-labeled small organic molecules $\left({ }^{14} \mathrm{C}\right.$-acetate and ${ }^{3} \mathrm{H}$-lysine $)$ in thick and thin filaments indicates that at least a fraction of the symbionts can switch to mixotrophic metabolism, depending on available energy and/or carbon sources (Ponsard et al. 2013). Genes for acetate assimilation were identi- fied in the symbiont metagenomes (Jan et al. 2014, Jiang et al. 2020).

2.1.5.2. Sulfur metabolism. Sulfide oxidation was initially proposed as the sole metabolism of the symbiotic population (Wirsen et al. 1993), based on (1) the phylogeny of the symbionts (thought to belong to a single campylobacterial phylotype, Polz \& Cavanaugh 1995), (2) the high level of $\mathrm{H}_{2} \mathrm{~S}$ at the Snake Pit site from where the shrimp and their bacteria were first described and (3) the observation of internal sulfur granules in shrimp ectosymbionts (Gebruk et al. 1993).

Successful amplification of several genes coding for subunits of key enzymes involved in the oxidation of sulfur compounds confirmed the occurrence of this type of metabolism within the epibiotic community: (1) genes coding for the adenosine-5'-phosphosulfate reductase (aprA), related to Gammaproteobacteria sulfur oxidizers and to Deltaproteobacteria sulfate reducers (Zbinden et al. 2008, Hügler et al. 2011) and (2) genes coding for sulfate thiohydrolase (SoxB), related to Campylobacteria (Hügler et al. 2011). Through metagenomic approaches, numerous Sox genes (Sox$A Z Y X, \operatorname{SoxB}, \operatorname{Sox} W)$ and aprA genes affiliated to Campylobacteria and Gammaproteobacteria were also found (Jan et al. 2014). Dsr genes (coding for the dissimilatory sulfate reductase) were found in Gammaproteobacteria (Jan et al. 2014). This enzyme is known to promote the oxidation of stored elemental sulfur, and could in this case be used to take advantage of the reserves of intracellular elemental sulfur (Zbinden et al. 2008):

$$
\begin{aligned}
& \text { Dsr Apr } \\
& \mathrm{H}_{2} \mathrm{~S} \rightarrow \text { Sulfite }\left(\mathrm{H}_{2} \mathrm{SO}_{3}\right) \rightarrow \text { APS } \rightarrow \text { Sulfate }\left(\mathrm{H}_{2} \mathrm{SO}_{4}\right) \\
& \text { Sox }
\end{aligned}
$$

where APS is adenosine-5'-phosphosulfate reductase.

Hügler et al. (2011) highlighted the co-occurrence of sulfur-oxidizing and sulfur-reducing epibionts among the symbiont community, suggesting that they may be involved in a syntrophic exchange of sulfur compounds, which could increase the overall efficiency of the Rimicaris exoculata cephalothoracic epibiotic community. More recently, genes implicated in the disproportionation of inorganic sulfur compounds were identified in the deltaproteobacterial epibiont 'Candidatus Desulfobulbus rimicarensis' metagenome (Jiang et al. 2020). In this latter case, sulfur compounds (thiosulfate, sulfide, elemental sulfur) can be used as electron donors or acceptors depending on their degree of oxidation, which expands metabolic epibiont capabilities and may avoid substrate competition. 
2.1.5.3. Methane oxidation. Aerobic methanotrophs can be recognized by their characteristic intracytoplasmic membrane stacking system in which methane oxidation occurs. Such morphotypes have been observed in $R$. exoculata epibionts from the Rainbow site, using TEM (Zbinden et al. 2008) and FISH (Guri et al. 2012). Bacterial 16S rDNA gene sequences obtained from these samples clearly belong to known methanotrophic Gammaproteobacteria symbionts (like Bathymodiolus symbionts) (Zbinden et al. 2008). Furthermore, particulate methane monoxygenase (pmoA) genes affiliated to the methylotrophic Gammaproteobacteria class (Methylomonas sp., Methylobacter sp. and Bathymodiolus pmoA gene sequences) were obtained (Zbinden et al. 2008).

Using ${ }^{14} \mathrm{C}$-labeled methane incubation, Polz et al. (1998) failed to detect methane utilization in shrimp branchiostegites or scaphognathites from Snake Pit samples. The levels of $\mathrm{CH}_{4}$ in the fluid, and consequently the proportion of this type of metabolism among the bacterial community, are probably too low at Snake Pit to detect any activity. Such activity could possibly be measured at ultramafic sites like Rainbow or Logatchev. Indeed, if the ratio of $\mathrm{CH}_{4}: \mathrm{H}_{2} \mathrm{~S}$ in the fluids is less than 1 (as at Snake Pit), the thiotrophic symbionts in the mussel Bathymodiolus azoricus dominate, whereas if this ratio is higher than 2 (as at Rainbow or Logatchev), the methanotrophs dominate (Salerno et al. 2005). This may be true for $R$. exoculata symbionts as well, but remains to be tested.

2.1.5.4. Iron oxidation. Oxidation of sulfide and methane has long remained the only bacterial autotrophic chemosynthetic metabolism described in hydrothermal vent symbionts. However, the exceptional enrichment in iron in Rainbow fluids (see Table 2) and the fairly abundant and rusty mineral deposits surrounding the bacteria of the shrimp branchial chamber at that site (see Fig. 3d) suggest that iron oxidation could be another potential metabolism (Zbinden et al. 2004). Long based on indirect suggestions, a large body of evidence now indicates that iron oxidation must be present within the epibiosis. In oxic environments, spontaneous ferrous iron oxidation is extremely rapid at ambient temperature $\left(25^{\circ} \mathrm{C}\right.$ ) and neutral pH (Emerson \& Moyer 1997, Neubauer et al. 2002). Under these conditions, Feoxidizing bacteria may be unable to compete with the abiotic processes. However, in the shrimp environment, the temperature is usually lower than $25^{\circ} \mathrm{C}$, and oxygen is reduced to about two-thirds of its level in air-saturated seawater (Zbinden et al. 2004). Under such conditions, abiotic oxidation is much slower. Based on the kinetic study of Millero et al. (1987),
Zbinden et al. (2004) calculated that the half-life of ferrous iron would be about $35 \mathrm{~h}$ in a shrimp environment. Considering that the upper pre-branchial chamber (housing the main ectosymbiotic bacterial community) is located downstream of the gills in the water flow, leading to a $\mathrm{pH}$ reduction, a $\mathrm{CO}_{2}$ increase and an $\mathrm{O}_{2}$ decrease due to shrimp respiration, the abiotic oxidation rate should thus be even slower (Zbinden et al. 2004). Moreover, since the rusty minerals only appear following a recolonization of the branchial chamber by bacteria after each molt (Corbari et al. 2008a) and because of their tight association with microbial cells (Gloter et al. 2004, Anderson et al. 2008, Corbari et al. 2008b), a neutrophilic ironoxidizing bacterial origin is strongly suspected.

Other data are in line with a bacterial origin of iron oxides. The very homogeneous composition and the uncommon mixed-valence of the nanocristalline 2line ferrihydrite (Gloter et al. 2004) of these iron oxides are characteristic of bacteriogenic iron oxyhydroxides (Kennedy et al. 2004). Iron polyphosphate granules were detected inside some thin filamentous epibionts (Zbinden et al. 2008). Such granules are widely distributed in prokaryotes, and could serve as ATP substitutes, energy storage units or chelators of metal ions (Kornberg 1995). An iron storage role has been suggested here to fuel the metabolism in case of iron depletion in the environment. Shrimp maintenance in a pressurized aquarium without iron supply indeed led to the emptying of most of the granules (Zbinden et al. 2008). Finally, this hypothesis is supported by the fact that a $6 \mathrm{~h}$ shrimp incubation in the presence of ferrous iron increases the ${ }^{14} \mathrm{C}$-carbon fixation rate, showing that ferrous iron contributes to fueling $R$. exoculata epibionts (Ponsard et al. 2013).

Molecular data were recently obtained regarding the occurrence of iron-oxidizing bacteria among the epibionts, revealing members of the Zetaproteobacteria through a metagenomic approach and FISH observations (Jan et al. 2014). Thus far, all characterized Zetaproteobacteria are iron oxidizers, able to grow at circumneutral $\mathrm{pH}$ and under microaerophilic conditions, resulting in the precipitation of large amounts of Fe-oxyhydroxides (Emerson et al. 2007, Jan et al. 2014, Scott et al. 2015, Henri et al. 2016). Furthermore, homologs of genes expressed during iron oxidation by Acidithiobacillus ferrooxidans (a molybdopterin oxidoreductase $\mathrm{Fe}_{4} \mathrm{~S}_{4}$ region and ferredoxin encoding gene) were identified in the partial metagenome of Zetaproteobacteria epibionts of shrimp (Jan et al. 2014).

Based on geochemical calculations, Schmidt et al. (2008a) showed that at the Rainbow site, iron oxida- 
tion appears to be the major energy source for chemosynthesis, due to its exceptional enrichment in fluids. However, kinetic modeling (Schmidt et al. 2009) suggested successive stages of iron oxide deposition, being first microbiologically driven and followed by an abiotic iron oxidation. The initial bacterial ferrihydrite deposition, which is a strong catalyst for abiotic iron oxidation, would favor the subsequent abiotic deposition. In the earliest stage of the molting cycle, the formation of iron oxyhydroxides would then be dominated by iron-oxidizing bacteria, and the resulting accumulation of biogenic iron oxide would subsequently favor abiotic iron oxidation and inhibit microbial growth.

2.1.5.5. Hydrogen. Hydrogen powers primary production in bacterial symbionts of the hydrothermal vent mussel Bathymodiolus puteoserpentis, from the Logatchev site on the MAR (Petersen et al. 2011). High concentrations of hydrogen are present in the fluids of ultramafic systems. It is a particularly favorable electron donor, as the energy yield from hydrogen oxidation is much higher than that from methane oxidation, sulfur oxidation and all other potential electron donors for chemolithoautotrophic growth under standard conditions (Petersen et al. 2011).

The key enzymes involved in hydrogen metabolism are hydrogenases, which catalyze the reaction: $\mathrm{H}_{2} \rightarrow$ $2 \mathrm{H}^{+}+2 \mathrm{e}^{-}$. The HupL gene, encoding the large subunit of a [NiFe] hydrogenase, was successfully amplified in $R$. exoculata and sequences were affiliated to Campylobacteria and Deltaproteobacteria relatives (Hügler et al. 2011). Jan et al. (2014) also found several hydrogenase genes $\left(\mathrm{H}_{2}\right.$ uptake and $\mathrm{H}_{2}$ sensing) and relatives in the Campylobacteria and Gammaproteobacteria partial metagenome, suggesting that both dominant epibionts have the potential to use hydrogen as an energy source. Recently, the deltaproteobacterial epibiont 'Candidatus Desulfobulbus rimicarensis' was also proposed to be capable of hydrogen oxidation (Jiang et al. 2020). Measures of $\mathrm{H}_{2}$ consumption in the shrimp incubation medium (as demonstrated for $B$. puteoserpentis gill tissues by Petersen et al. 2011) or an increased carbon incorporation rate by $R$. exoculata bacteria in the presence of hydrogen (as shown in the presence of sulfide and iron by Ponsard et al. 2013) would prove that at least part of the symbiotic bacteria actually carry out this metabolism.

2.1.5.6. Metabolism plasticity. Since the concentration of major electron donors varies greatly among the end-member fluids at the different sites colonized by $R$. exoculata (see Table 2), it is likely that the activity level of metabolic pathways related to those compounds varies accordingly within the epibiosis.
The energy budget provided by the oxidation of the various potential electron donors greatly depends on local environmental conditions, notably their concentrations, temperature and $\mathrm{pH}$ (Zbinden et al. 2004), which will define the energy that can be derived from the different oxidative pathways (Schmidt et al. 2008a). Using geochemical calculations, Schmidt et al. (2008a) determined the most favorable energy metabolism for the Rainbow and TAG sites. At Rainbow, iron oxidation appears to be the major energy source, due to its exceptional enrichment in fluids. The energy yield of hydrogen oxidation depends on how fast it reacts with oxygen, but could be in the same range as for iron oxidation. Sulfide and methane only represent secondary energy sources for microbial primary production at that site. At TAG, sulfide oxidation is the major energy source for microbial primary production; iron oxidation could still be substantial, while methane represents only a minor part of the primary production (Schmidt et al. 2008a). At the Logatchev vent field, aerobic hydrogen oxidation could provide up to 7 times more energy per kilogram of vent fluid than methane oxidation, and up to 18 times more energy per kilogram of vent fluid than sulfide oxidation, based on a thermodynamic model (Petersen et al. 2011). These data indicate that the chemical energy pathways used by $R$. exoculata branchial chamber symbionts differ depending on the fluid chemistry at a site, highlighting metabolic plasticity in the shrimp-microbe symbiosis.

In the light of all of these results, we can now consider the branchial chamber epibiont community of $R$. exoculata as a functional consortium, composed of different morphotypes and phylotypes, and possessing different complementary metabolisms. In summary, compiling all of these data, the following scheme can be drawn (Fig. 6):

(1) The bacterial community is numerically dominated by filamentous Campylobacteria and Gammaproteobacteria (respectively 39 and $30 \%$ of the bacterial sequences of the metagenome; Jan et al. 2014).

(2) Campylobacteria appear as thick filaments and some thin filaments. Both filament types are chemoautotrophic sulfur-oxidizers, using the Sox pathway for energy generation and the rTCA cycle for carbon fixation ( $S o x B$ and aclA gene sequences, respectively). Some of the Campylobacteria also possess hydrogenase genes and may use hydrogen oxidation for energy generation. Thick and thin filaments incorporate small organic molecules (acetate and lysine), indicating that at least a fraction of these symbionts can switch to mixotrophic metabolism, depending on available energy and/or carbon sources. 


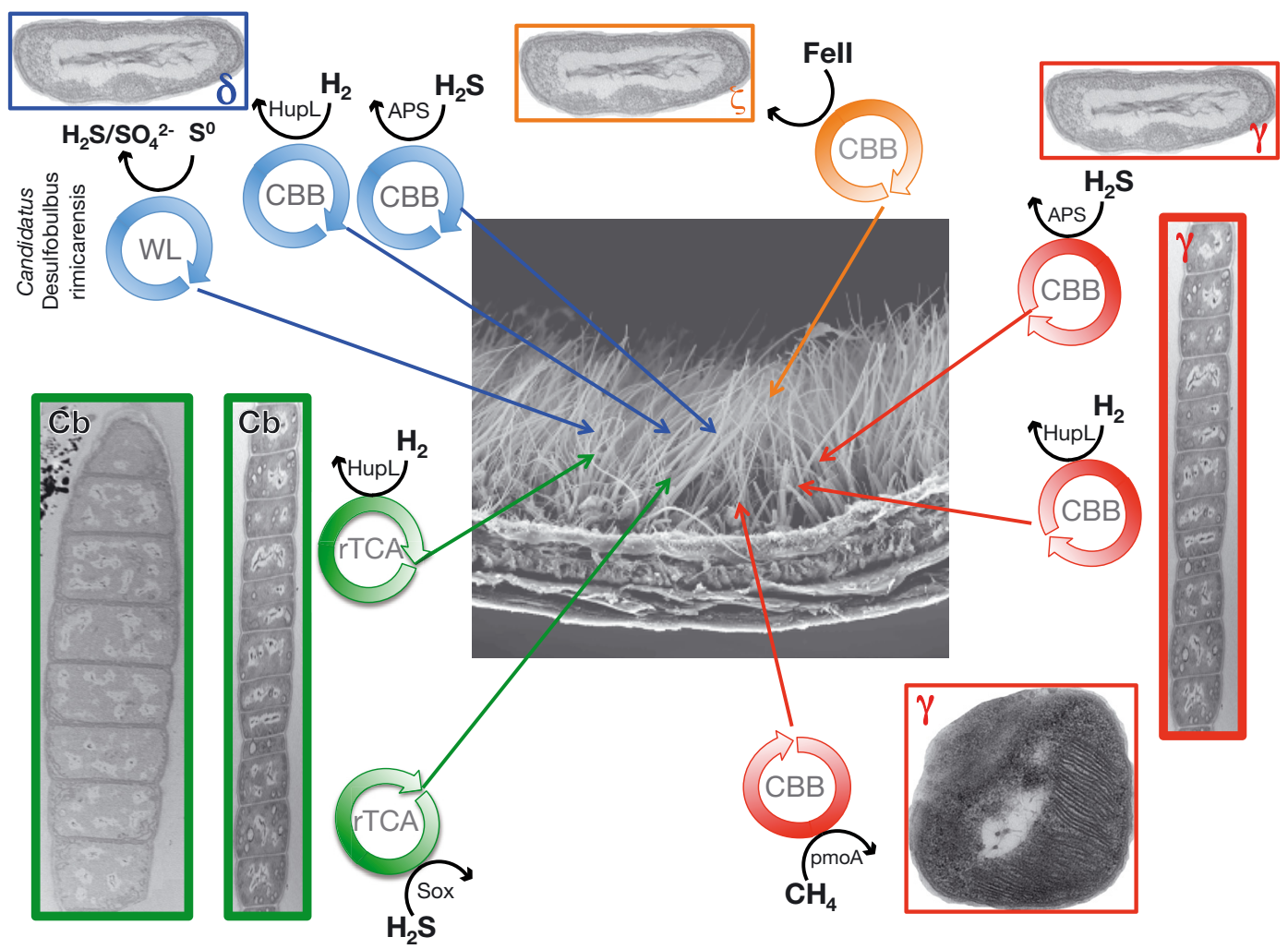

Fig. 6. Summary scheme of the diversity and functioning of the Rimicaris exoculata branchial chamber symbiosis. Dominant phylotypes are indicated by thicker boxes. Sox: sulfate thiohydrolase; HupL: [NiFe] hydrogenase; APS: adenosine-5'phosphosulfate reductase; pmoA: particulate methane monoxygenase, A-subunit; rTCA: reductive tricarboxylic acid cycle; CBB: Calvin-Benson-Bassham cycle; WL: Wood-Ljungdahl pathway; Cb: Campylobacteria; $\gamma, \zeta, \delta$ : respectively Gamma-, Zetaand Deltaproteobacteria. Colors differentiate the phylotypes

(3) Gammaproteobacteria appear as thin filaments and rod-shaped bacteria. They are chemoautotrophic sulfur-oxidizers, using the APS pathway for energy generation and the CBB cycle for carbon fixation (aprA/Sox and $c b b M$ gene sequences, respectively). Gammaproteobacteria also occur as coccoid-shaped cells with intracytoplasmic membranes, characteristic of type I methanotrophs, using methane oxidation for energy generation and probably also using the CBB cycle for carbon fixation.

(4) Zetaproteobacteria appear as rod curved bacteria and are chemoautotrophic iron-oxidizers (identified by a molybdopterin oxidoreductase $\mathrm{Fe}_{4} \mathrm{~S}_{4}$ region and ferredoxin encoding genes), using the CBB cycle for carbon fixation (cbbM genes).

(5) Deltaproteobacteria appear as small cocci and possess aprA and hydrogenase genes, suggesting they can grow lithotrophically, using the Wood-Ljungdahl pathway. They can use both sulfide and hydrogen as electron donors for sulfate and/or sulfur reduction and are capable of disproportionation of inorganic sulfur compounds.

Observed diversity may depart from this general scheme as the relative abundance of the different phylotypes and/or the importance of different metabolic pathways may differ among sites (especially between basaltic and ultramafic sites). Plasticity could also depend on the molt stage, as shrimp seem to be predominantly colonized by Campylobacteria after the exuviation, while later molt stages appear to be dominated by Gammaproteobacteria (Petersen et al. 2010). More work is required to elucidate the functioning of this plasticity, which appears to enable the co-occurrence of similar metabolism, with no evidence of bacterial competition and maybe even cooperation. Complementary studies are underway through metagenomic but also metatranscriptomic approaches, together with the development of deepsea sampling tools in order to better access in vivo functioning of this complex symbiosis.

\subsection{Digestive tract symbionts}

\subsubsection{Digestive tract anatomy and content}

Morphological descriptions of the digestive tract of $R$. exoculata reveal a small stomach with few grind- 
ing structures, suggesting low mechanical digestive activity (Segonzac et al. 1993, Durand et al. 2010). The midgut, i.e. the central digestive absorption zone deprived of a cuticle, represents two-thirds of the total length of the digestive tract, and is significantly longer than in most crustaceans (Durand et al. 2010).

The first studies examining the digestive tract of $R$. exoculata reported a high sulfur mineral content, typical of chimney walls (chalcopyrite $\left[\mathrm{CuFeS}_{2}\right.$, pyrite $\left[\mathrm{FeS}_{2}\right]$ and sphalerite $[\mathrm{ZnS}]$ ), along with iron oxides (Van Dover et al. 1988, Segonzac et al. 1993) (Fig. 7a,b). Elevated bacterial densities were also reported in the stomach $\left(10^{9}\right.$ cells per ml of stomach content, Van Dover et al. 1988) and still increasing in the mid- and hindgut (Polz et al. 1998). A high $\mathrm{CO}_{2}$ fixation rate in the mid- and hindgut (Polz et al. 1998) suggested the occurrence of a highly active chemoautotrophic bacterial community that could use the gut polymetallic sulfide content as an energy source (Pond et al. 1997a). These bacteria could be a nutritional source, through either a classical digestion process or by essential dietary component supply or synthesis of organic molecules (Pond et al. 1997a).

Shrimp cuticle fragments were also observed in the gut content (Zbinden et al. 2004). The consumption of freshly molted exuviae to ingest associated bacte- ria was suggested. But as the bacterial coverage decreases beneath the iron oxide crust before the molt (Zbinden et al. 2004, Corbari et al. 2008a), it seems more likely that $R$. exoculata eats the exuvium to recover the minerals (e.g. calcium) contained in the cuticle, as observed in other crustaceans (Steel 1993, Corbari et al. 2008a).

\subsubsection{Bacterial localization and morphological diversity}

Stomach bacteria seem to be subject to a digestion process, as bacterial DNA and lipopolysaccharides were detected (Van Dover et al. 1988, Durand et al. 2010), but SEM and TEM observations failed to detect intact microorganisms (Van Dover et al. 1988, Zbinden \& Cambon-Bonavita 2003). Intact rods and cocci were observed within the gut content (Zbinden $\&$ Cambon-Bonavita 2003). Some of them are probably transient, but some may be part of a specific resident microflora (Zbinden \& Cambon-Bonavita 2003, Durand et al. 2010, Cowart et al. 2017).

A dense bacterial community of thin and long $(0.2 \mu \mathrm{m} \times 15 \mu \mathrm{m})$ single-celled bacteria is also present between the microvilli of the midgut epithelium

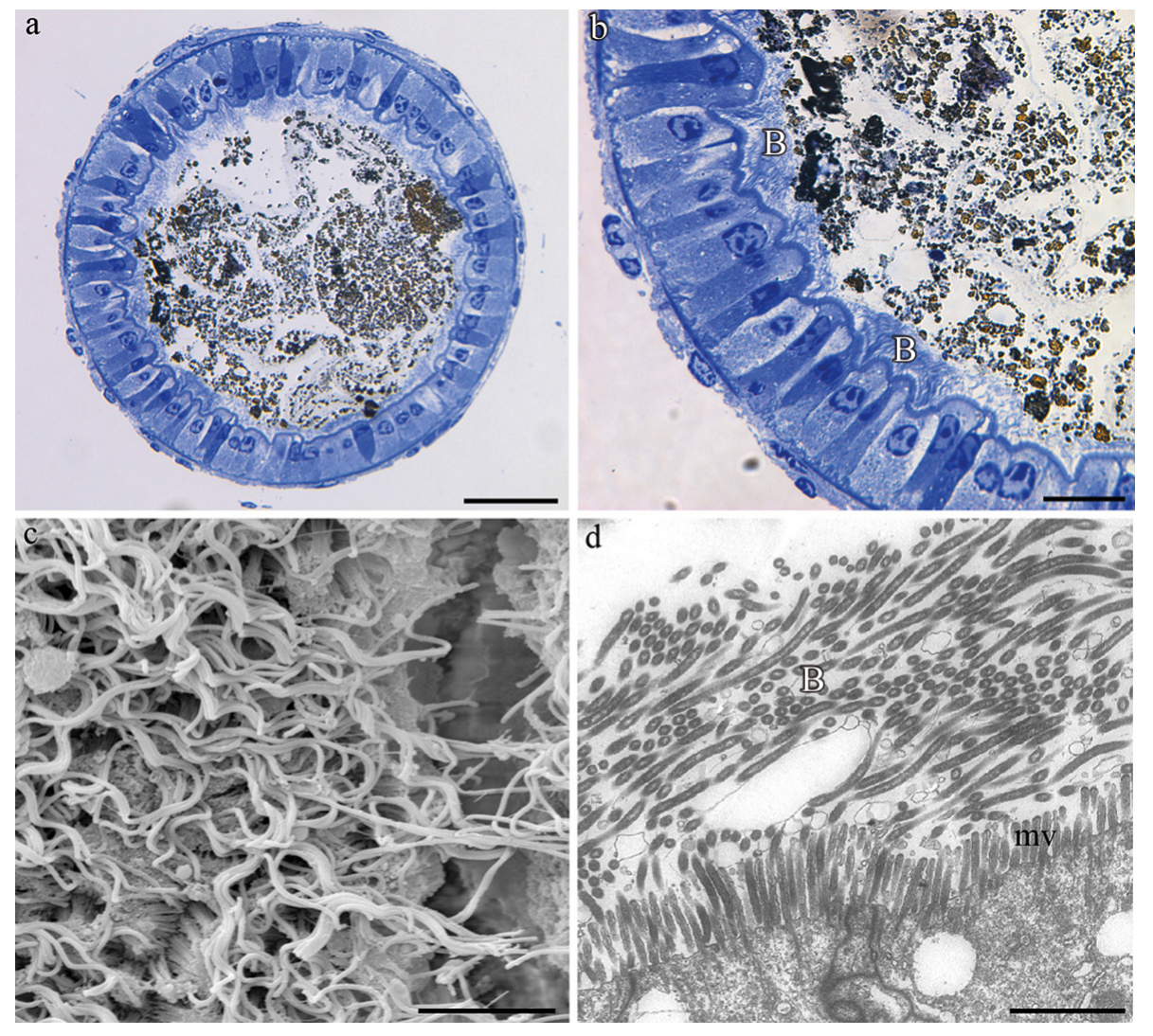

Fig. 7. Rimicaris exoculata gut epibionts. (a) Semi-thin section in the midgut showing the black and brown mineral particles (respectively iron sulfides and oxides). (b) Closer view of the epithelium, showing the abundance of filamentous epibiotic bacteria (B) all around the section. (c) Scanning electron microscopy view of the epibionts (picture by L. Durand). (d) Transmission electron microscopy observations of the bacterial gut epibionts (B) inserted between the microvilli (mv). Scale bars $=50 \mu \mathrm{m}$ (a), $20 \mu \mathrm{m}$ (b), $5 \mu \mathrm{m}$ (c), $2 \mu \mathrm{m}$ (d) 
(Durand et al. 2010) (Fig. 7c,d). This community is separated from the bolus by the peritrophic membrane and is thus not part of the shrimp diet, at least not through a digestion process. As the midgut is deprived of cuticle, and thus not subject to exuviation, this probably favors long-term microbial colonization and interactions of this resident microbial community with its host (Durand et al. 2010). Possibly under host control of bacterial invasion, filamentous epibiont cells would grow, along with their host, without division, leading to this long, single-celled, filamentous morphology. Further investigations are required to confirm this hypothesis (Durand et al. 2015).

\subsubsection{Bacterial phylogenetic diversity}

The bacterial diversity in the midgut is largely represented by 3 major groups: Deferribacteres, Mollicutes and Campylobacteria. Gammaproteobacteria are also present to a lesser extent (Zbinden \& Cambon-Bonavita 2003, Durand et al. 2010, Cowart et al. 2017). This diversity is relatively restricted compared to the environmental one (Durand et al. 2015). The 3 main lineages were still present after a $72 \mathrm{~h}$ starvation experiment leading to the complete elimination of the bolus, and were consequently designated as resident epibionts (Durand et al. 2010) rather than transient microflora. The 2 former phylotypes, absent from the environment (except for 1 clone retrieved from an environmental sample collected close to shrimp aggregations; Hügler et al. 2011), could be a specific and selected bacterial resident community (Zbinden \& Cambon-Bonavita 2003, Durand et al. 2010, 2015). Conversely, gut and branchial chamber Campylobacteria epibionts are similar, suggesting that a part of gut Campylobacteria could be directly acquired from the branchial chamber and/or the environment, and may thus be a transient community remaining due to a permanent ingestion process (Durand et al. 2015). In vivo experiments using radiolabeled ${ }^{14} \mathrm{C}$-bicarbonate have revealed poor digestive incorporation, suggesting that Campylobacteria, and to a lesser extent Gammaproteobacteria, would not be active at least under autotrophic conditions (Ponsard et al. 2013).

As no specific hybridization response has been obtained yet on the thin filamentous bacteria inserted between the microvilli, their phylotype assignation remains uncertain (Durand et al. 2010). A $72 \mathrm{~h}$ starvation experiment showed a low representation of Deferribacteres in the resulting clone library, sug- gesting that the filaments (which were unaffected by the starvation) would not belong to this group. Being mostly anaerobic and iron dependent, Deferribacteres may have lysed during the experiment, which does not fit natural conditions, preventing any definitive conclusion (Durand et al. 2010). Furthermore, it should also be noted that the Deferribacteres haplotype is mostly dominant at the Rainbow site, but less represented at TAG and even less at Logatchev (Cowart et al. 2017), whereas microscopic observations revealed the same occurrence of filamentous bacteria at these 3 sites (Durand et al. 2015). The thin filaments were also suspected to belong to Mollicutes, based on their morphology, but this has not been confirmed, as FISH attempts have been unsuccessful thus far (Durand et al. 2010, 2015). More work has still to be done using metagenomic and metatranscriptomic approaches in order to properly identify these filamentous bacteria and to reveal their potential role in holobiont fitness.

\subsection{Symbiont transmission}

\subsubsection{Branchial chamber symbionts}

The cyclic occurrence of aposymbiotic (before the symbiont acquisition) and symbiotic phases in the host life cycle is intrinsic to horizontally transmitted symbioses (Bright \& Bulgheresi 2010). When present, larvae are also aposymbiotic during their pelagic dispersal (Bright \& Bulgheresi 2010). To date, no bacteria have been observed inside eggs of $R$. exoculata, but Gammaproteobacteria and Campylobacteria have been reported on their surface (Guri et al. 2012, Cowart et al. 2017, Methou et al. 2019). In the same way, bacterial symbionts appear to be absent in the branchial chamber of post-hatching larvae of $R$. exoculata (Guri et al. 2012, Hernandez-Avila et al. 2015) or in their first juvenile stages after recruitment (Komai \& Segonzac 2008). Some Campylobacteria and Gammaproteobacteria sequences retrieved from Rainbow seawater samples were closely related (99\% similarity) to epibiont sequences from the branchial chamber of shrimp from the same site (Guri et al. 2012). A free-living form of the Campylobacteria symbiont was also detected in substantial proportions at the Snake Pit site (Polz \& Cavanaugh 1995). Finally, using a $16 \mathrm{~S}$ rDNA gene, segregation by site was observed among Campylobacteria and Gammaproteobacteria symbionts (Petersen et al. 2010, Durand et al. 2015), which was also supported using Lux genes (Le Bloa et al. 2017). These results suggest 
the existence of horizontal (environmental) transmission for the shrimp branchial chamber epibionts, acquired in each generation and after each molt (Petersen et al. 2010). Potential symbionts may not always be abundant in the environment. For this reason, many aquatic hosts actively pump water against their tissues, enhancing the chance of entrapping potential symbionts (Bright \& Bulgheresi 2010). The water currents generated by scaphognathite beating in the branchial chamber of $R$. exoculata may similarly enhance environmental colonization by symbionts.

\subsubsection{Gut symbionts}

Free-living Campylobacteria and Gammaproteobacteria are commonly identified in hydrothermal ecosystems, but the gut community of these groups in $R$. exoculata displays a lower diversity than in the environment (Flores et al. 2011). The gut symbionts could thus be acquired from the environment, but with a selective process (Durand et al. 2015). On the other hand, no Deferribacteres (Durand et al. 2015, Cowart et al. 2017) and only 1 sequence affiliated to Mollicutes (Hügler et al. 2010) were retrieved from the environment. The strong similarity of Deferribacteres associated with shrimp (>99\%), regardless of site, suggests a specific long-term association between these bacteria and their host (Durand et al. 2015). Both their absence in the environment and the long-term association suggest vertical transmission of these symbionts. As previously mentioned, no bacteria have ever been observed inside the eggs (Guri et al. 2012, Cowart et al. 2017). Thus another, horizontal, transmission pathway is suggested. Epibionts could be acquired at early juvenile stages through anus-to-mouth fluid exchange with adults (proctodeal trophallaxis) (Durand et al. 2015), as observed in some social insects with intestinal symbionts, such as termites or cockroaches (Salem et al. 2015).

\subsection{Ectosymbiosis and molt cycle}

In the shrimp, as in other arthropods, growth occurs through cyclic molts, during which the cuticle is regularly renewed. At ecdysis, when the entire old cuticle is shed, the bacterial community of the branchial chamber is shed with it, and a new bare cuticle covers the freshly molted shrimp. As direct continuous observations during the molt cycle are not possible at hydrothermal sites, estimation of the absolute duration of the molt cycle (in days) can only be determined indirectly, averaged over an entire sample. The percentage of individuals at each molting stage was determined using the Drach method (Drach \& Tchernigovtzeff 1967) and corresponds to the relative duration (in percentage of the absolute total duration of the complete molt cycle) of the stage (Corbari et al. 2008a). By compiling data from the literature, Corbari et al. (2008a) showed that the anecdysial period (stage $\mathrm{C}_{4}$ ) varied considerably in different shrimp species of comparable size, whereas the pre-ecdysial period (stages $\mathrm{D}_{0}-\mathrm{D}_{4}$ ) was similar. Comparison with known cycles of similar-sized coastal shrimp allowed these authors to estimate that the interval between 2 successive exuviations in $R$. exoculata (Fig. 8a) could be as short as $10 \mathrm{~d}$ (compared to $21 \mathrm{~d}$ for Penaeus japonicus or 48-91 d for Macrobrachium rosenbergii) (Corbari et al. 2008a).

The abundance and distribution of the bacterial coverage are related to the molting cycle and depend on the time elapsed since the last molt (Zbinden et al. 2004, Corbari et al. 2008a). Bacterial re-colonization begins just after the exuviation, with only scarce and randomly distributed patches of short thin filaments and rods (Fig. 8b,c). Rapid bacterial growth quickly (within $2 \mathrm{~d}$ ) leads to a dense bacterial mat composed of long thin and thick filaments (Corbari et al. 2008a). Evolution of bacterial coverage until the next molt consists mainly of the gradual accumulation of mineral deposits, mainly composed of iron oxides (see Section 2.1.5.4) at Rainbow and associated with iron sulfides at TAG (Corbari et al. 2008a). These mineral deposits ultimately turn into a thick crust isolating the bacterial community from the external environment (Fig. 8d,e) (Corbari et al. 2008a). A rapid molting rate is usually regarded as an antifouling mechanism contributing to the elimination of epibiotic bacteria (Bauer 1989). The rapid molting frequency in $R$. exoculata is thought to be critical in eliminating the mineral crust that isolates the bacteria from the reduced compounds of the fluid on which they rely, thus allowing the recolonization of a new and efficient fueling symbiotic community (Corbari et al. 2008a).

The color of the adult shrimp exoskeleton evolves throughout the molt cycle due to progressive mineral deposits in the branchial chamber. Color evolves from white and translucent specimens in post-ecdysis (Fig. 8b) to light red and finally dark red specimens in pre-ecdysis (Fig. 8d) at the Rainbow site, where only iron oxides are deposited. At TAG, where the fluid contains more sulfide and less iron than at Rainbow, grey shrimp appear between white and light red individuals in the molt cycle. The grey color corresponds to iron sulfide deposits on the bacterial 


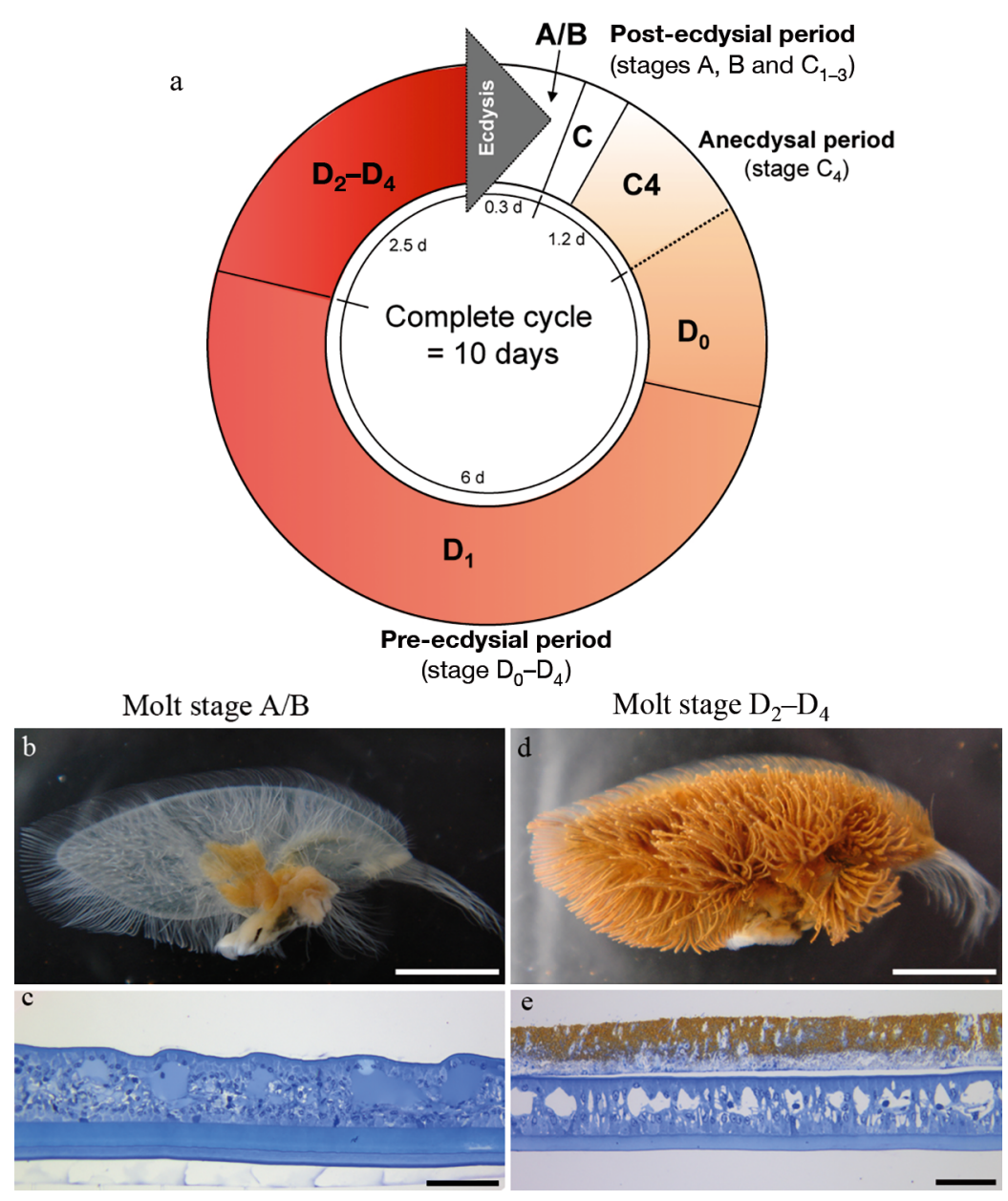

Fig. 8. (a) Rimicaris exoculata molt cycle with duration of the different stages (graphic courtesy of L. Corbari). (b,d) Coloration pattern of scaphognathites (specimens from the Trans-Atlantic Geotraverse [TAG] site) and (c,e) semithin sections of the branchiostegite (specimens from the Rainbow site) illustrating the bacterial and mineral coverage of a specimen in the A/B stages

$(\mathrm{b}, \mathrm{c})$ and the $\mathrm{D}_{2}-\mathrm{D}_{4}$ stages $(\mathrm{d}, \mathrm{e})$. Scale bars $=5 \mathrm{~mm}(\mathrm{~b}, \mathrm{~d}), 100 \mu \mathrm{m}(\mathrm{c}, \mathrm{e})$

biofilm. Late pre-ecdysial individuals are also dark red at TAG (Corbari et al. 2008a). Color can thus be used as a convenient proxy to determine specimen molting stage (Corbari et al. 2008a).

The bacterial community of the digestive tract is located in the midgut, devoid of cuticle, and thus is not submitted to the molt cycle. This symbiotic community does not need to be renewed from scratch at each molt.

\subsection{Host-symbiont interactions}

\subsubsection{Host-symbiont recognition}

The first essential step in the establishment of a symbiosis with horizontal transmission is the bilateral recognition of host and symbiont. The diversity of the epibiotic community of the $R$. exoculata branchial chamber is very stable in time and space (Zbinden et al. 2008, Petersen et al. Guri et al. 2012), and is reduced compared to the environmental bacterial diversity (Flores et al. 2011). It can therefore be assumed that a subset from the pool of diverse environmental free-living bacteria is selected during the stages of colonization. Host-bacteria recognition is usually facilitated by host lectin-like (or other types of) surface molecules that produce adhesion receptors that recognize and bind microbe-associated molecular patterns present on the microbial surface (Liu et al. 2019). In invertebrates, all symbiotic lectins identified to date belong to the subgroup of C-type lectins (CTLs), like in the nematode Laxus oneistus or the clam Codakia orbicularis, which both harbor sulfur-oxidizing symbionts (Bulgheresi et al. 2006, Gourdine et al. 2007). A CTL was identified in $R$. exoculata, termed RCTL (Liu et al. 2019), predominantly expressed in symbiotic (compared to non-symbiotic) tissue, reflecting its main function of agglutinating symbionts therein (Liu et al. 2019). A recombinant protein (rRCTL) was used for bacterial binding experiments on species of Campylobacteria (Arcobacter nitrofigilis) and Gammaproteobacteria (Escherichia coli). The results showed that the IRCTL recognizes and agglutinates only the Gammmaproteobacteria, but not the Campylobacteria species (Liu et al. 2019). Unlike conventional crustacean CTLs (i.e. non-symbiosis-related, pathogen-oriented lectins), rRCTL did not affect the normal growth of the bacteria that had been recruited and could thus play a role in the recognition and enrichment of the Gammaproteobacteria symbionts (Liu et al. 2019).

\subsubsection{Quorum sensing perception and biofilm formation}

The selection of a subset of microbial types from the environment could also result from interactions/ regulation between the epibionts themselves. In a 
biofilm such as that in the branchial chamber of $R$. exoculata, bacteria communicate with each other through the secretion of signaling molecules, such as the quorum sensing pathway, to coordinate the biofilm formation, exopolysaccharide production, virulence or cell aggregation (Montgomery et al. 2013). Genes coding for such signaling molecules (luxS in Campylobacteria and luxR in Gammaproteobacteria) were revealed in epibionts of the $R$. exoculata branchial chamber through a metagenomic study (Jan et al. 2014), but the expression of luxS and luxR genes was only detected for the pre-molting stages, at the peak of bacterial colonization (Le Bloa et al. 2017). Quorum sensing in the $R$. exoculata branchial chamber epibiosis could regulate bacterial growth to avoid an excessive development of the biofilm. It could also be involved in the dispersal of the epibiont biofilm, liberating some bacteria from the biofilm in the proximal environment of the shrimp just before the molt so that these bacteria can recolonize the freshly molted shrimp (Le Bloa et al. 2017).

Genes encoding proteins involved in attachment to surfaces (type IV pili, O antigen) and genes encoding for flagella, implied in bacterial motility and chemotaxis, were evidenced in the $R$. exoculata epibiont metagenome (Jan et al. 2014). They may be involved in Campylobacteria and Gammaproteobacteria attraction to the host and biofilm formation within the branchial chamber of the shrimp (Le Bloa et al. 2017).

\subsubsection{Pathogen recognition and non-proliferation of symbionts}

To maintain its epibiosis, the shrimp must at the same time select its epibionts among microbial communities, regulate their proliferation and prevent colonization by non-beneficial bacteria or pathogens. Permanently exposed to a large density and diversity of microorganisms, marine animals in general, and $R$. exoculata in the present case, must have an effective immune system to control microbial growth. Devoid of any specific immune system, shrimp rely only on innate immunity, a non-specific, rapid defense oriented towards all external aggressions (Rosa \& Barracco 2010). Part of this defense occurs through antimicrobial peptides (AMPs), small-sized molecules naturally produced by all living organisms, which act as a first line of defense against bacterial infection (Rosa \& Barracco 2010, Tasiemski et al. 2014). The first AMP isolated from a deep-sea hydrothermal species was described in the polychaete Alvinella pompejana (Tasiemski et al. 2014), which harbors a dense epibiotic community on the dorsal expansions of its tegument (Gaill et al. 1984) and therefore shares similarities with $R$. exoculata (Segonzac et al. 1997). Tasiemski et al. (2014) showed that AMP targets specifically one type of bacteria (the most abundant) but has no effect on the others, suggesting that this AMP (alvinellacin) selects and shapes the $A$. pompejana epibiotic microflora and prevents microbiota from proliferating. Gu et al. (2018) characterized another AMP (which they named RspALF1, for Rimicaris sp. anti-lipopolysaccharide factor) in a Rimicaris species from the Manus Basin. RspALF1 is mostly expressed in hepatopancreas and gills (but bacteriophore tissues, i.e. branchiostegite and scaphognathite, were not tested). RspALF1 exhibits anti-microbial activity, in vitro and in vivo, against a wide range of Gram-negative and Gram-positive bacteria, by binding to the cell wall components and damaging bacterial cellular structures. RspALF1 is more effective (i.e. inhibiting bacterial growth at lower concentrations) on bacteria isolated from the Manus Basin deep-sea hydrothermal vent field than on neritic bacteria. Anti-fungal activity was also demonstrated for RspALF1. Le Bloa et al. (2020) identified an AMP in $R$. exoculata, which they named $R e-$ crustin. Re-crustin is mainly synthesized in the tissues on which the ectosymbiotic community of the branchial chamber develops, i.e. the branchiostegite and scaphognathite. As it is mostly expressed at the juvenile stage, Re-crustin has been proposed to be involved in symbiont attraction and adhesion (Le Bloa et al. 2020). AMPs could thus also play a role in host symbiont recognition and not just in the regulation of their proliferation.

All of these data lead to the hypothesis that there could be a stringent recognition system between the shrimp and its branchial chamber symbionts and strict control by the shrimp of the selected bacteria allowing a phylogenetically almost identical recolonization in the branchial chamber after each molt (Le Bloa et al. 2017).

\section{PHYSIOLOGY}

\subsection{Respiration}

Rimicaris exoculata features 10 pairs of phyllobranchiate gills, with single-layered branchial lamellae bordered by a thin cuticle $(0.3-0.5 \mu \mathrm{m})$ (Martinez et al. 2005). The gills do not appear to be involved in osmoregulation (which seems only mediated by the epipodites in the branchial chamber), considering the 
lack of $\mathrm{Na}^{+}-\mathrm{K}^{+}$ATPase (Martinez et al. 2005). Gills are mainly involved in respiration, but a detoxification activity also occurs in the gills through sulfide-oxidizing bodies (Compère et al. 2002; see Section 3.4).

Living within steep chemical and thermal gradients, where hot, reduced hydrothermal fluid mixes turbulently with oxygenated seawater (Schmidt et al. 2008a), shrimp are exposed to highly fluctuating oxygen conditions, sometimes to hypoxic conditions. For example, $\mathrm{O}_{2}$ concentrations of $63-236 \mu \mathrm{M}$ have been measured in discrete samples of fluid in the vicinity of shrimp aggregations (Zbinden et al. 2004). For comparison, concentrations of 242 and $12.4 \mu \mathrm{M}$ were measured from ambient seawater and a black smoker outlet at the Rainbow site, respectively (Zbinden et al. 2004). Few studies have been devoted to respiratory adaptations of $R$. exoculata (Lallier \& Truchot 1997, Lallier et al. 1998), and to a broader extent to crustaceans at hydrothermal vents (Arp \& Childress 1981, Sanders et al. 1988, Lallier et al. 1998, Chausson et al. 2001, 2004). Ravaux et al. (2003) measured oxygen consumption rates of $0.837-1.094 \mathrm{mg} \mathrm{O}_{2} \mathrm{~g}^{-1}$ dry mass $\mathrm{h}^{-1}$ for $R$. exoculata at in situ pressure conditions (23 $\mathrm{MPa})$ and at oxygen levels of the deep seawater surrounding the North Atlantic vent sites. These values are in good accordance with the relationship between oxygen consumption and dry mass obtained for crustaceans (see references in Ravaux et al. 2003).

The respiratory pigment of decapod crustaceans is hemocyanin (Hc), which reversibly binds oxygen to a pair of copper atoms. The Hc of $R$. exoculata is composed mostly of hexameric molecules (89\%) of $469 \pm$ $9 \mathrm{kDa}$ (Lallier \& Truchot 1997). For a majority of crustaceans, $\mathrm{Hc}-\mathrm{O}_{2}$ affinity is relatively low, with oxygen partial pressure at half-saturation $\left(\mathrm{P}_{50}\right)$ values $>10$ Torr under physiological conditions (Truchot 1992). For example, $\mathrm{P}_{50}=27$ Torr at $\mathrm{pH} 7.8,10^{\circ} \mathrm{C}$ for the coastal shrimp Palaemon elegans (Bridges et al. 1984). However, $\mathrm{Hc}-\mathrm{O}_{2}$ affinity is rather well correlated with ambient oxygen content of the environment (Sanders \& Childress 1990, Truchot 1992), and Hc affinity for oxygen of species living in hypoxic environments is higher than for those living in normoxic conditions. Lallier \& Truchot (1997) showed that $R$. exoculata Hc has a high oxygen affinity $\left(\mathrm{P}_{50}=\right.$ 3 Torr at $\mathrm{pH} 7.5,15^{\circ} \mathrm{C}$ ), which is also the case for Segonzacia mesatlantica, the endemic crab of the MAR vent sites $\left(\mathrm{P}_{50}=2.2\right.$ Torr at $\mathrm{pH} 7.5,15^{\circ} \mathrm{C}$, Chausson et al. 2004), and for other vent endemic crustacean species (Hourdez \& Lallier 2007). R. exoculata Hc also showed almost no temperature effect on $\mathrm{P}_{50}$ in the range $15-35^{\circ} \mathrm{C}$, a large Bohr effect (oxygen affinity increases with $\mathrm{pH}$ ) and a moderate lactacte (main end-product of anaerobiosis in Crustacea) effect (oxygen affinity increases with lactate) (Lallier \& Truchot 1997). This is favorable in an environment where temperature and oxygen contents considerably fluctuate (Lallier et al. 1998). Lallier \& Truchot (1997) also highlighted that native hemolymph shows a lower affinity for $\mathrm{O}_{2}\left(\mathrm{P}_{50}=6\right)$ than when dialysed, suggesting the occurrence of a dialyzable factor in $R$. exoculata hemolymph that decreases Hc-oxygen affinity. The high affinity would thus allow better oxygen extraction in a frequently hypoxic environment, while the decrease in $\mathrm{pH}$ and the possible presence of other factors would increase the release of the oxygen to the tissues by decreasing the affinity of Hc for oxygen (Lallier et al. 1998).

\subsection{Sensory perception}

\subsubsection{Localization of hydrothermal emissions}

Since the very first publications describing hydrothermal vents, the question of the localization of vent emission by endemic species was put forward. Corliss et al. (1979, p. 1079) noted that 'there are many questions to be answered about these animal communities. One concerns how they locate and colonize new vents.' $R$. exoculata faces recognition of active hydrothermal sites at different times of its life. After dispersal in the water column, larvae need to find a vent site to settle and begin their development toward adult life (Pond et al. 1997b, Herring \& Dixon 1998). As adults, shrimp have to navigate in the environment, find fluids fueling their symbiotic bacteria, or just remain in an appropriate range of physicochemical conditions (Desbruyères et al. 2000, 2001). Temperature, dim light emitted by vents, chemical compounds like sulfide or acoustic vibrations induced by hydrothermal fluid emissions have been proposed as navigational cues for the detection of hydrothermal vents (Van Dover et al. 1989, Segonzac et al. 1993, Renninger et al. 1995, Gaten et al. 1998a,b, Crone et al. 2006), but few studies have reported clear results on these assumptions.

3.2.1.1. Vision. As hydrothermal environment is devoid of light and as shrimp eyes present obvious modifications, the vision of the so-called 'eyeless shrimp' has been relatively well studied. Adults of $R$. exoculata (as well as Mirocaris fortunata, R. chacei and Alvinocaris markensis) lack the usual externally differentiated eye (eye-stalk) of shrimp, having instead a pair of large, highly reflective, dorsal 
organs (Van Dover et al. 1989). These unusual eyes (see arrows in Fig. 2b) have no image-forming optics, but a solid wall of light-sensitive rhabdom consisting of 3500 photoreceptors (containing rhodopsin). Beneath the rhabdomeral segments, a thick white diffusing layer (tapetum) increases, by reflection, the quantity of light captured by the retina (O'Neill et al. 1995, Nuckley et al. 1996, Kuenzler et al. 1997, Lakin et al. 1997, Wharton et al. 1997, Jinks et al. 1998, Chamberlain 2000). These features are mostly understood as an adaptation for detection of extremely faint sources of light emitted by the vents (thermal radiations or sonoluminescence, i.e. glow produced by imploding bubbles of gas at high pressure; Pelli \& Chamberlain 1989, Van Dover et al. 1989, 1996). The eyes of alvinocaridid shrimp present a clear evolution between the larvae and adults (also observed in the hydrothermal vent crab Bythograea thermidron, Jinks et al. 2002) from an imaging retina to the nonimaging retina of the adults: the zoeal eye is similar (eye-stalk) to those of other surface-dwelling decapod larvae (Gaten et al. 1998a,b), suggesting that the early stages are planktonic (Gaten et al. 1998b). Intense lights (and notably those of submersibles used for the collection) were shown to induce irreversible retinal damage in hydrothermal shrimp (Rimicaris exoculata and Mirocaris fortunata), with complete loss of the rhabdom layer (Herring et al. 1999).

3.2.1.2. Chemoreception. Chemoreception in decapods encompasses 2 modalities: the 'olfaction,' mediated by olfactory receptor neurons of specialized unimodal olfactory sensilla (the esthetascs), restricted to the lateral flagella of the antennules (Laverack 1964, Grünert \& Ache 1988, Cate \& Derby 2001), and the 'distributed chemoreception,' mediated by numerous bimodal sensilla (innervated by both mechano- and chemoreceptor neurons) occurring on all appendages (Schmidt \& Mellon 2011, Mellon 2014, Derby et al. 2016). Renninger et al. (1995) suggested increased sensory capabilities in hydrothermal species due to the fact that the non-esthetasc bimodal chemosensilla of $R$. exoculata antenna were more numerous and innervated by 4 to 5 times more dendrites than in the coastal shrimp Penaeus aztecus. Zbinden et al. (2017) described a higher diversity of non-esthetasc setal types in the coastal shrimp Palaemon elegans than in several hydrothermal shrimp species. However, the role of these sensilla is still poorly known, and whether their diversity corresponds to a multiplicity of perceived stimuli remains an open question (Cate \& Derby 2001). Focusing on esthetasc sensilla of $R$. exoculata, Zbinden et al. (2017) revealed no specific adaptation regarding the size or number of esthetascs between hydrothermal and coastal species. The anatomical features of esthetascs do not reveal striking differences between hydrothermal and coastal species, whether in terms of (1) cuticle thickness, which relates to permeability and thus to the ability to detect odor molecules, or (2) the number of olfactory sensory neurons and dendrites, which relates to the odorant discrimination ability (Machon et al. 2018). A specificity of hydrothermal species ( $M$. fortunata and $R$. exoculata) is the occurrence of numerous pore-like structures in the esthetasc cuticle, absent from the coastal species, which could facilitate the passage of odor molecules through the cuticle to the olfactory receptors of the neurons (Machon et al. 2018). IR25a, an olfactory co-receptor, is expressed in the lateral antennular flagella, bearing the olfactory sensilla of the esthetascs, but also to a lesser extent in the medial antennular flagella and the antennae in $R$. exoculata (Zbinden et al. 2017). Molecular studies are underway to further investigate adaptations of hydrothermal species by identifying, quantifying and localizing the different chemoreceptors expressed by olfactory sensory neurons (Zbinden et al. 2017).

Electroantennography detection of food-related odor and sulfide (but only at the high concentrations encountered in the pure fluid), via both antennae and antennules, were evidenced in hydrothermal shrimps ( $R$. exoculata and Mirocaris fortunata), as well as in coastal species (Penaeus aztecus and Palaemon elegans) (Renninger et al. 1995, Machon et al. 2018). Nevertheless, detection of the same chemical can trigger different behavioral reactions according to species. Renninger et al. (1995) observed in situ strong orientation behavior to a piece of sulfide removed from the chimney but reported unpublished data of Sofranko and Van Dover showing avoidance behavior to sulfide solution in the coastal shrimp Palaemonetes vulgaris.

A recent study investigated the brain architecture of adult $R$. exoculata (Machon et al. 2019). This study shows, as one would expect, a small visual area, as already observed in blind cave crustaceans (Stegner et al. 2015). Surprisingly, however, as opposed to most blind animals that rely on olfaction as a major sensory modality, $R$. exoculata also exhibits a small olfactory area. The striking features of the $R$. еxосиlata brain are the especially well developed higher brain centers (the hemiellipsoid bodies), which integrate all of the sensory information and are considered high-order learning and memory centers (Maza 
et al. 2016). The unusual development of this brain part has also been observed in crustaceans with sophisticated navigation skills or spatial memory (like Panulirus argus, Sandeman et al. 2014, or mantis shrimp, Wolff et al. 2017). This suggests that adult $R$. exoculata may strongly rely on peculiar navigation skills with learning of place memory to locate in its environment and memorize emission sites of hydrothermal fluids, rather than on vision or chemodetection (Machon et al. 2019). A study of the brain architecture of larvae and juveniles is underway to determine whether the sensory modalities of early life stages differ from those of adults.

3.2.1.3. Thermoreception. Even though the thermal biology of $R$. exoculata has been investigated (see Section 3.3), very few studies have been conducted on thermosensibility. Peripheral specific or putative multimodal thermoreceptors are not known in crustaceans (Ache 1982). Nevertheless, $R$. exoculata seem able to detect thermal differences, as they avoid extreme thermal temperatures, showing quick escape behavior when coming in contact with hydrothermal fluid (Segonzac et al. 1993, M. A. Cambon-Bonavita \& M. Zbinden unpubl. data). In addition, behavioral studies have shown that $R$. exoculata can discriminate temperatures in a gradient and is attracted by the hot points $\left(10^{\circ} \mathrm{C}\right)$ in a cold environment $\left(2{ }^{\circ} \mathrm{C}\right.$, Ravaux et al. 2009).

\subsubsection{Biotic interactions}

For most crustaceans, chemodetection is the dominant sensory modality used in all important biological processes. Various chemical cues are used for the recognition of conspecifics, individual identity, social status or aggressiveness, for the localization of sexual partners and for the identification of injured or diseased conspecifics or in order to avoid predators (Derby \& Weissburg 2014). To date, no data are available about such social interactions in $R$. exoculata aggregations. Known predators of $R$. exoculata are crabs (Segonzacia mesatlantica), gastropods (Phymorhynchus sp.), Actiniaria, bathyal fishes and possibly R. chacei (Gebruk et al. 1997a,b, 2000, Van Dover 2000, Colaço et al. 2002).

\subsection{Thermal biology}

The extreme trophic specialization of $R$. exoculata appears to force the shrimp to live close to superheated fluid discharges (Gebruk et al. 1997a). Dam- age (black burnt cuticles) caused by contact with superheated fluid has been observed on many specimens (Van Dover et al. 1988, Gebruk et al. 1993, 2000, Segonzac et al. 1993; Fig. 1). The proportion of damaged specimens with burnt pereopods, pleopods or antennae at the TAG site ranged from 33 to $50 \%$ of the population (Gebruk et al. 1997a, Vereshchaka et al. 2000). Shrimp were often observed deviating very suddenly when entering in contact with hot fluid. Vereshchaka et al. (2015) related the efficiency of the shrimp escape behavior to a morphological characteristic of $R$. exoculata, which possess 2 strong movable spines instead of 1 on the tail fan.

These organisms thrive not only near very hot fluid outlets, but also in an environment where the thermal variability is the highest among aquatic habitats (Bates et al. 2010). What is the upper thermal limit tolerated by this shrimp, and what are the molecular mechanisms and/or behavioral strategies involved to cope with such deleterious temperatures and their fluctuations (Ravaux et al. 2019)? Answers to these questions came with the development of pressure aquaria allowing in vivo experiments (Ravaux et al. 2003, 2009, Cottin et al. 2010a,b, Shillito et al. 2014, Ravaux et al. 2019). The $R$. exoculata upper thermal limit (critical thermal maximum, CTmax) was first proposed to be in the $33-37^{\circ} \mathrm{C}$ range (Ravaux et al. 2003), but was later recalculated by Shillito et al. (2006) as $38.5 \pm 2{ }^{\circ} \mathrm{C}$. This species can therefore not sustain prolonged exposure at this temperature, and has also been proven to trigger a heat stress response through the over-expression of the stress gene $h s p 70$ when exposed for $1 \mathrm{~h}$ to $30^{\circ} \mathrm{C}$. No response was triggered when exposed to $20^{\circ} \mathrm{C}$, or for shorter time exposure, whereas a 10 min shock peaking at $39^{\circ} \mathrm{C}$ also yielded a heat stress response (Cottin et al. 2010a, Ravaux et al. 2019). In addition to the molecular response to heat shock, $R$. exoculata presents 2 kinds of behavioral response to heat stress: (1) an escape response at temperatures above $24^{\circ} \mathrm{C}$ (Ravaux et al. 2003) and (2) thermoregulation behavior via increased activity among the swarm, leading to a mix between hot hydrothermal vent and cold seawater in their surroundings maintaining an optimal temperature in the swarm (Ravaux et al. 2019). This has previously been described for social insects like bees or wasps that cool the colony by wing fanning (Jones \& Oldroy 2006). R. exoculata may therefore choose a microhabitat in a relatively narrow thermal window that would be defined by its nutritional demands, thermal tolerance and thermal preference, as evidenced by the low level of hsp70 expression in natural populations (Ravaux et al. 2019). 
Similar to their host, $R$. exoculata epibionts are punctually subjected to bursts of very hot temperatures. To date, however, only few data are available on their thermal sensitivity. Genes encoding heat shock proteins were recently identified in the metagenome for Campylobacteria, Gammaproteobacteria and Zetaproteobacteria epibionts, indicating their possible ability to cope with the fluctuating conditions of the hydrothermal habitat (Jan et al. 2014).

\subsection{Detoxification}

Hydrothermal vent invertebrates are surrounded by fluids containing numerous potential chemical threats, such as sulfide (a cellular respiration poison), methane and dissolved heavy metals like iron, copper, zinc, cadmium and lead (Charlou et al. 2002). An excessive accumulation of metals in the cells can lead to the formation of reactive oxygen species and cause severe cell damage. Hydrothermal fauna have developed adaptations to deal with these toxic compounds, excreting them from their bodies or storing them in less toxic forms (Childress \& Fisher 1992, Rousse et al. 1998). The question of detoxification is all the more topical in the present circumstances, where the various metals (e.g. Cu, Ni, Zn, Mn, Co, $\mathrm{Ag}, \mathrm{Au}$ ) contained in the massive hydrothermal sulfide deposits are of growing economic interest to mining industries (Gramling 2014, Mengerink et al. 2014). It is likely that exploitation activities will expose the local fauna to intense plumes of sediments, metals and various chemical compounds (Van Dover 2014; see Section 6 on potential threats).

Various detoxification mechanisms have been suggested or described for $R$. exoculata. Metals can be stored as insoluble, non-circulating forms, thus avoiding disturbance of essential metabolic functions (Geret et al. 2002). For example, copper and sulfur are accumulated in the epithelial cells of the $R$. exoculata hepatopancreas as insoluble granules, thus decreasing the potential toxic effect of $\mathrm{Cu}$ present in the cytoplasm of cells (Auguste et al. 2016). Hepatopancreas and gills are the 2 tissues that accumulate the most trace metals, in concentrations that reflect their concentrations in the vent fluid (Geret et al. 2002, Kádár et al. 2006, Auguste et al. 2016). The most accumulated metals in $R$. exoculata soft tissues are Fe, $\mathrm{Zn}, \mathrm{Mn}$ and $\mathrm{Cu}$, whilst $\mathrm{Ag}$ and $\mathrm{Cd}$ are accumulated less (Gonzalez-Rey et al. 2008). However, compared with the concentration in their environment, only $\mathrm{Cu}$ and $\mathrm{Cd}$ are bioaccumulated (Geret et al. 2002). $R$. exoculata experimental exposure to 0.4 and $4 \mu \mathrm{M}$ of
$\mathrm{Cu}$ in pressurized aquaria did not show significant differences in $\mathrm{Cu}$ concentrations in the tissue analyzed between the 2 treatments, which could indicate a potential regulation mechanism of metal metabolism by the shrimp (Auguste et al. 2016). Compared with coastal shrimps, low levels of arsenic (Larsen et al. 1997, Taylor et al. 2012) and mercury (Martins et al. 2001, Kádár et al. 2006) have been detected in $R$. exoculata, probably related to their short food chain, which limits the accumulation of toxic compounds in tissues. Moreover, compared to Mirocaris fortunata that lives farther away from vent fluids, $R$. exoculata had similar or often less metal accumulated in selected organs, possibly the result of a higher degree of adaptation to hydrothermal conditions (Kádár et al. 2006), or a shorter food chain.

Sulfide detoxification was proposed to occur in the gill epithelium of the shrimp via sulfide-oxidizing bodies, electron-dense organelles containing membrane stacks (Compère et al. 2002). Such structures were also observed in different tissues of organisms from sulfide-rich habitats, such as the gills of the clam Solemya reidi or the hindgut and tegumental tissues of the echiuran worm Urechis caupo, in which enzymatic oxidation of sulfide to less toxic thiosulfate was demonstrated (Compère et al. 2002 and references therein). Iron detoxification was also proposed to occur in the gills of $R$. exoculata, thanks to a ferritin (H-ferritin RexFrtH) which rapidly converts and stores the ferrous iron contained in the fluid passing over the gills in a less toxic ferric form (Liu et al. 2019).

Another detoxification process, the metallothioneins (MTs), cystein-rich, low molecular weight proteins with a high affinity for physiological $(\mathrm{Zn}, \mathrm{Cu}, \mathrm{Se})$ or xenobiotic (Cd, Hg, As, Ag) metal cations, have been proposed to be involved in binding metals and could also act as oxyradical scavengers, protecting cells against reactive oxygen species (Roesijadi 1992). Induction of metallothioneins was observed in the shrimp gill after an experimental exposure to $4 \mu \mathrm{M}$ of $\mathrm{Cu}$, probably linked to the role of MTs in the detoxification and/or storage of $\mathrm{Cu}$ (Auguste et al. 2016), but the presence of MTs, as well as activities of several antioxydant enzymes in control shrimp, showed the existence of constitutive mechanisms of protection against metal toxicity (Auguste et al. 2016). Compared to Mirocaris fortunata, R. exoculata showed much higher MT levels (approximately 6-fold higher), suggesting a higher exposure to metals, but lower antioxidant activities (Gonzalez-Rey et al. 2007). A possible explanation is that metal-induced reactive oxygen species are less likely to be formed when MT synthesis increases, leading to a natural decrease in 
the antioxidant enzymatic protections (Gonzalez-Rey et al. 2007).

Following hypotheses proposed for Alvinella pompejana filamentous epibionts on the EPR (CossonMannevy et al. 1988), detoxicating properties have also been proposed for the shrimp symbiotic bacteria at MAR (Segonzac et al. 1993, Jan et al. 2014). Due to their metabolic activities, symbionts convert harmful compounds such as sulfide, nitrite or FeII to other less toxic compounds, which in return may have a beneficial effect for their host. Some granules and polysaccharides synthesized by symbionts may also play a role in metal chelation (Jan et al. 2014). However, further investigations are needed to elucidate the role of symbionts in detoxification, including deeper metagenomics studies, transcriptomic and in vivo experiments.

\section{REPRODUCTION AND DISPERSAL}

\subsection{Oogenesis and reproductive cycle timing}

Based on specimens recovered at different periods of the year (June-July, September and November), Copley et al. (2007) and Ramirez-Llodra et al. (2000) respectively observed a continuous range in oocyte size-frequency distributions, from $R$. exoculata individuals with only small oocytes $(76-108 \mu \mathrm{m})$ to individuals with much larger ones (466-601 $\mu \mathrm{m})$. These findings led the researchers to conclude asynchronous gametogenesis. Copley et al. (2007) suggested a lack of seasonal reproduction in Rimicaris exoculata due to similar median sizes of oocytes in their 2 samplings (September and November), whereas Ramirez-Llodra et al. (2000) observed that females collected in September had larger oocytes than those collected in June, arguing for a more advanced stage of development. Sampling in August to October revealed that many of the females had well-formed eggs in their gonads and were ready to spawn (at the TAG and Broken Spur sites, Vereshchaka et al. 1998), whereas sampling in January and March showed brooding females, eggs and hatched larvae (at the Logatchev site, Guri et al. 2012; at the TAG site, Hernandez-Avila et al. 2015). Combining all these data argues for seasonal reproduction in R. exoculata (Hernandez-Avila 2016), with spawning occurring in late fall (October-November), females brooding embryos during winter and larvae hatching in the late winter to early spring (JanuaryMarch). Seasonal reproduction has also been described for 2 other alvinocaridid species: $R$. hybisae, from the Mid-Cayman spreading center (Nye et al. 2012) and Alvinocaris stactophila, from the Brine Pool cold seep in the Gulf of Mexico (Copley \& Young 2006).

\subsection{Brooding and fecundity}

In most caridean shrimps, females spawn soon after copulation, and mature oocytes are transferred to pleopods where they are fertilized by the stored sperm (Correa \& Thiel 2003). In decapods, copulation (which, to our knowledge, has never been observed in $R$. exoculata) takes place after ecdysis, and the ovigerous females incubate the eggs, until hatching, on the pleopods, between the lateral sclerites that are usually enlarged at the pre-spawning molt to create a brood chamber (Ramirez-Llodra et al. 2000). Brooding females of $R$. exoculata have only recently (2007) been collected (M.-A. Cambon-Bonavita pers. data), despite numerous sampling cruises to all colonized sites since the discovery of the species in 1986. For example, Vereshchaka et al. (1998) noted that $R$. exoculata is represented in Russian collections by thousands of individuals, among which brooding females are absent. This absence was linked to seasonal breeding and sampling efforts almost entirely restricted to the summer months (Gebruk et al. 1997a, Herring 1998, Vereshchaka et al. 1998, Ramirez-Llodra et al. 2000, Guri et al. 2012, Hernandez-Avila et al. 2015, Hernandez-Avila 2016). It was also suggested that ovigerous $R$. exoculata leave the aggregations around high temperature vents, where samples are generally collected, to protect the embryos from hydrothermal fluids and from the risk of mechanical damage caused by the highly active shrimp aggregations (Ramirez-Llodra et al. 2000). Brooding females were finally collected among the shrimp aggregations, first in March 2007 at the Logatchev site (Guri et al. 2012) and more recently from January to March 2014 and 2018, at the TAG and Snake Pit sites (Hernandez-Avila et al. 2015, Methou et al. 2019). This supports the first hypothesis of seasonal reproduction.

Within $R$. exoculata broods, the embryos develop synchronously and all eggs are at the same stage, which can differ from one female to another (RamirezLlodra et al. 2000, Guri et al. 2012). Egg sizes of 0.2$0.4 \mathrm{~mm}$ (Guri et al. 2012), $0.6 \mathrm{~mm}$ (Ramirez-Llodra et al. 2000) and 0.8-1 mm (Vereshchaka et al. 1998) have been reported, probably reflecting different stages of embryo development. A few fecundity values have also been published to date: 988 eggs for 1 female (Ramirez-Llodra et al. 2000, who also reported a 
value of 836 eggs for 1 female from the $\mathrm{PhD}$ thesis of J. Copley).

\subsection{Larval morphology and development strategy}

The first larvae of $R$. exoculata were sampled in March 2007 at the Logatchev site (Guri et al. 2012) and were described from a January 2014 collection at the TAG site (Hernandez-Avila 2016). They were obtained either from onboard hatching of brooding females or, using a larval pump, from the water column near adults (Hernandez-Avila et al. 2015). The detailed description of the first larval stage (zoea I) of $R$. exoculata brought important cues about the early life history of the species. The notable absence of both masticatory processes in the mandible and setation in mouthparts (which usually participate in the process of capture and manipulation of food) suggests that the $R$. exoculata first larval stage is a non-feeding larva (Hernandez-Avila et al. 2015). Both the lack of developed feeding structures and the accumulation of triacylgycerols, wax esters and monounsaturated fatty acids in eggs of alvinocaridid species (Pond et al. 1997c) support the occurrence of primary lecithotrophy in the early stage of alvinocaridids (Hernandez-Avila et al. 2015). Nevertheless, the size of the postlarvae and their photosynthetically derived fatty acid contents suggest that larvae must have fed and survive for extended periods as planktotrophic organisms (Pond et al. 1997b, 2000b, Allen-Copley et al. 1998, Dixon et al. 1998, Herring 1998). Combining these data suggests that the early lecithotrophic period would be followed by a feeding period during larval development (Hernandez-Avila et al. 2015).

It should be noted that Alvinocarididae is the only taxon among caridean decapods combining lecithotrophy in the first larval stage (suggested by undeveloped mouthparts) and extended larval development (suggested by the lack of pereiopods and pleopods). Indeed, in all other currently known cases of carideans, lecithotrophy is always associated with abbreviated development, as a mechanism of larval retention (Hernandez-Avila et al. 2015).

\subsection{Larval dispersal}

Given the apparent discontinuous nature of vent sites along the MAR (even if the number of active vent sites may be higher than actually reported, and may thus correspond to lower inter-site spacing, Baker et al. 2016), vent shrimp populations are faced with the threat of local extinction due to the seismic/ volcanic nature of hydrothermal emissions (Dixon et al. 1998). The strong convection current of hot water rising from the vents forms a buoyant plume that is likely to transport larvae away from vents in the water column (Tyler \& Young 2003). Along the MAR, the flow remains mostly in the axis of the ridge, constrained by the steep walls of the graben (Tyler \& Young 2003, Fouquet et al. 2010). Nevertheless, several geological structures could act as barriers against larval dispersal (such as the Atlantis and Kane Fracture Zones, the Azores islands, etc.). Active swimming and changes of buoyancy would seem necessary to rise above the basin and then sink down to a new site (Herring \& Dixon 1998).

Several facts suggest that $R$. exoculata larvae have high dispersal abilities that would facilitate longdistance colonization: (1) the lack of pereiopods and pleopods in the first zoeal stage suggests an extended larval development, (2) the large number of smallsized eggs (Ramirez-Llodra et al. 2000), together with the photosynthetically derived fatty acid contents of the postlarvae (Pond et al. 1997b) suggest that larvae feed for extended periods as planktotrophic organisms, and (3) the genetic analysis of adult $R$. exoculata from several sites that shows no significant genetic differentiation along the MAR (see Section 5). However, to date, no data on larval dispersal of $R$. exoculata are currently available, as the rare larvae collected off-site so far could not be definitively affiliated to a specific species. The data therefore concern Alvinocarididae as a whole. Using a midwater trawl, Herring \& Dixon (1998) collected unidentified alvinocarid shrimp post-larvae between 1990 and $3060 \mathrm{~m}$ around Broken Spur (without knowing if they were dispersing from the vent site or converging on it; Herring 1998). Although larval stages of some alvinocarid shrimp appear to feed on photosynthetically derived organic matter (Allen-Copley et al. 1998), it is still unclear which habitat the larval stages use (HernandezAvila et al. 2015). Although some Alvinocarididae early stages seem to tolerate large pressure variation and survive for a while at atmospheric pressure (Tyler \& Dixon 2000, Koyama et al. 2005), temperature seems to determine the upper limit of the bathypelagic habitat. Based on laboratory experiments, Tyler \& Dixon (2000) reported that $1 \mathrm{~atm}$ pressure (surface) and $20^{\circ} \mathrm{C}$ conditions are fatal to larvae of the shrimp Mirocaris fortunata. The alvinocarid larvae probably do not rise up to the euphotic zone, limited by the thermocline in their upward dispersal ( 200 $\mathrm{m}$ depth), and feed on particles descending to the aphotic zone (Tyler \& Dixon 2000, Hernandez-Avila et al. 2015). 


\subsection{Settlement}

The settlement stage is a key step in reproduction, where larvae have to find a location which confers high probability of survival and successful reproduction (Rittschof et al. 1998). Environmental (chemical and physical) cues, such as inorganic and organic compounds like conspecific odors, surface energy, vibration or light, determine where the larvae settle (Rittschof et al. 1998). At hydrothermal vents, sulfide, as an obvious signature for hydrothermal habitats, was proposed to be a settlement cue (Rittschof et al. 1998). In situ experiments at the Juan de Fuca Ridge confirmed attraction of alginate gels containing sulfide on larvae of vent polychaete worms (Cuomo 1985). However, to date, nothing is known on $R$. exoculata larvae settlement cues or sensory abilities. Vereshchaka (1997) indicated a settling stage between 3 and $5 \mathrm{~mm}$ in carapace length. The smallest stage A juvenile collected, close to adults, by Methou et al. (2020) was $5.7 \mathrm{~mm}$ in carapace length.

\subsection{Juveniles}

Upon examination of the abundant specimens of postlarval stages, covering a wide range of sizes (rostral carapace length between 4.8 and $17.4 \mathrm{~mm}$ ), Komai \& Segonzac (2008) described 4 ontogenetic stages (A, B, C and D-subadult), with a dramatic morphological change at size of 7-9 $\mathrm{mm}$ in carapace length. In a recent study, Methou et al. (2020) revised the ontogenetic description of $R$. exoculata larvae combining morphological observations and DNA identification. These authors proposed 3 ontogenetic stages, A, B and C-subadult. During these stages, no significant increase in size was noticed, with the shrimp probably spending most of its energy for great morphological changes rather than increases in body size (Komai \& Segonzac 2008). The most notable changes are the progressive reduction of the rostrum, the fusion of the eye-stalk, the inflation of the branchiostegite, the appearance of numerous plumose setae on the swelling scaphognathites and exopodites (Komai \& Segonzac 2008, Methou et al. 2020) and a gradual increase in bacterial abundance between 8 and $10 \mathrm{~mm}$ in carapace length (Vereshchaka 1996, Gebruk et al. 2000). Among the 519 juveniles examined from the July 1997 expedition, Shank et al. (1998) found no males and suggested that: (1) male sexual characteristics were not displayed by juveniles, or (2) $R$. exoculata could be a protogynous hermaphrodite. Komai \& Segonzac
(2008) reported that the smallest male they determined by the pleopod morphology was $10.1 \mathrm{~mm}$ in carapace length, corresponding to their stage $\mathrm{D}$, or subadults (stage C-subadults for Methou et al. 2020), corroborating the first hypothesis of Shank et al. (1998).

When arriving at vents, juveniles carry abundant stores of lipids of photosynthetic origin. The carbon stable isotope ratio $\left(\delta^{13} \mathrm{C}\right)$ showed a graded increase from juveniles, through smaller adults to the older specimens (Gebruk et al. 1997b, 2000, Polz et al. 1998, Methou et al. 2020), corresponding to the gradual introduction in the diet of carbon of bacterial chemosynthetic origin. There is also an increase in the proportion of the heavy isotope of nitrogen between the juvenile and the adult stages, which is probably due to epibiont metabolism processes using nitrate (Methou et al. 2020). The lipid data (Pond et al. 2000a,b, Allen et al. 2001), showing an evolution from photosynthetically derived n-3 fatty acids to bacterially derived n-4 fatty acids, also evidence a change in diet during metamorphosis and maturation (Gebruk et al. 2000). The transition between the 2 diets occurs at sizes $>10 \mathrm{~cm}$ carapace length, when juveniles are mostly sexually mature and have an inflated branchial chamber (Gebruk et al. 2000, Methou et al. 2020), probably mixing at the beginning the remaining reserves of accumulated photosynthetic carbon and carbon of bacterial origin.

Aggregations of hundreds to thousands of juveniles were reported in the vicinity $(1-5 \mathrm{~m})$ of the aggregations of $R$. exoculata, at lower habitat temperatures than the adults $\left(10\right.$ vs. $\left.28^{\circ} \mathrm{C}\right)$, in areas with lower hydrothermal flow, with the juveniles also being less active than the adults (Nuckley et al. 1996, Shank et al. 1998, Gebruk et al. 2000). Patches of juveniles (clearly visible due to their bright orange color) were also observed within adult aggregations, sometimes in direct proximity to fluid emissions (see white circle in Fig. 1). Their habitat could evolve with the progressive acquisition of the symbionts, their transition to a symbiotic diet and thus their requirements for fluid compounds.

Although knowledge on the reproduction and life cycle of $R$. exoculata has progressed in recent years (Hernandez-Avila et al. 2015, Hernandez-Avila 2016, Methou et al. 2019, 2020), there are still many unresolved questions. The main ones focus on the larval stages (larval life span, number of molts, distance, duration and area of dispersal), and on their recruitment (recognition factors for hydrothermal activity, recruitment stage) (Fig. 9). 


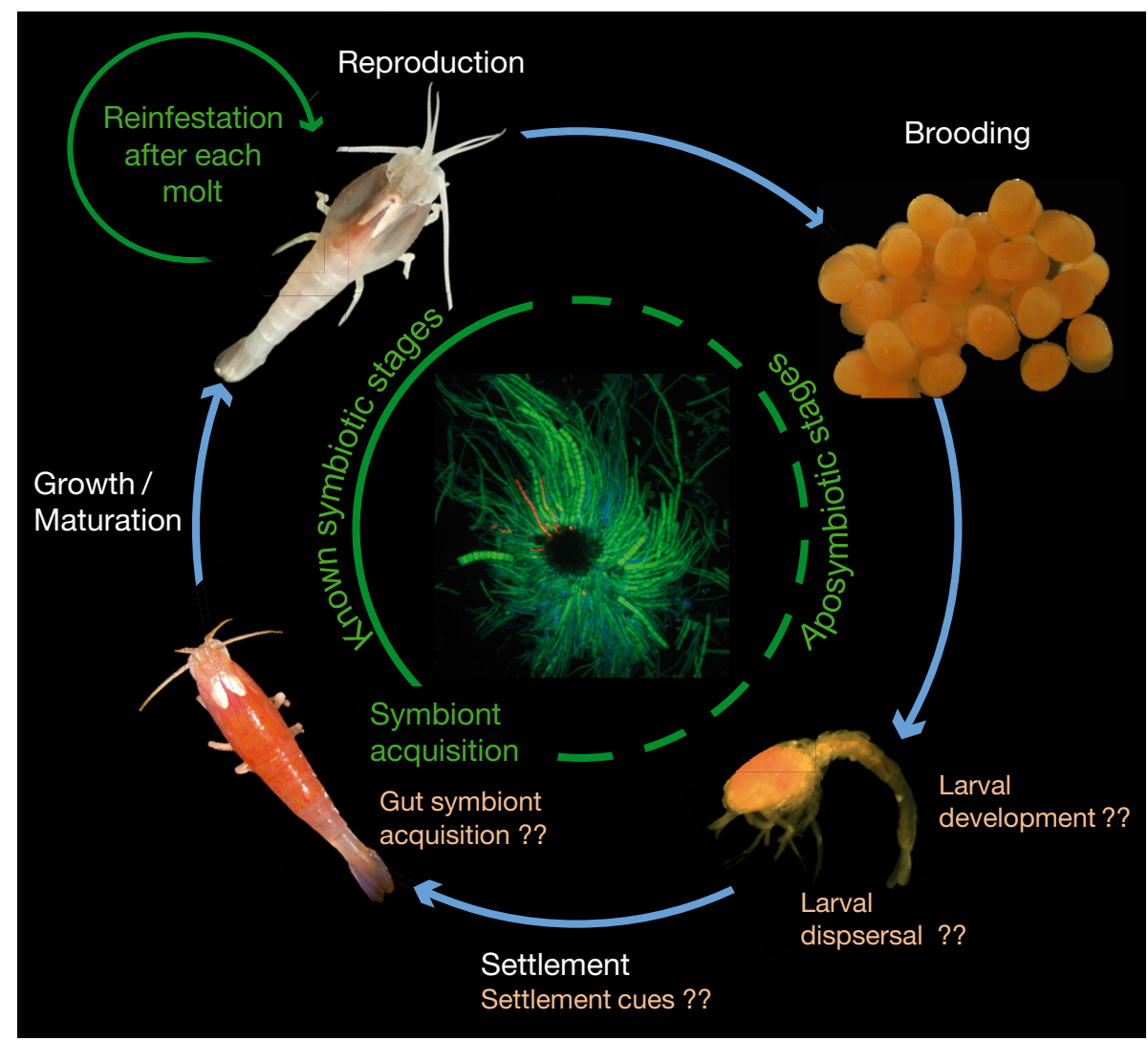

Fig. 9. Life cycle of the vent shrimp Rimicaris exoculata and its symbionts. Known symbiotic and aposymbiotic stages, for both gut and branchial chamber symbionts, are indicated. Branchial chamber symbionts are acquired by juveniles at a size range of 7-9 $\mathrm{mm}$ in carapace length. Gut symbionts are probably acquired at the juvenile stage, but no precise data are currently available.

Current major gaps in the knowledge of the shrimp life cycle are indicated by question marks

\section{BIOGEOGRAPHY AND CONNECTIVITY}

\subsection{Host biogeography and connectivity}

The discovery and faunal descriptions of hydrothermal vent sites all around the world gave rise to the description of biogeographic provinces based on faunal distribution (Van Dover et al. 2002, Moalic et al. 2012). Due to the discontinuous and ephemeral nature of these habitats, questions arose about colonization pathways and dispersal capabilities of hydrothermal vent communities. Indeed, the high rate of large-scale dispersal, although potentially generating a significant loss of larvae in the water column, ensures long-term persistence in these fragmented ephemeral habitats (Teixeira et al. 2011). Discontinuities of the ridges (transform faults and fracture zones), as well as hydrological barriers, are thought to impede the along-axis dispersal of a number of vent species and to favor allopatric speciation (Bachraty et al. 2009, Vrijenhoek 2010). The first study of Rimicaris exoculata biogeography (Creasey et al. 1996) was conducted using allozyme polymorphisms, between TAG and Broken Spur, 2 sites separated by $370 \mathrm{~km}$. The results showed no significant genetic differentiation, indicating a high gene flow between the 2 populations. The authors calculated a high migration rate between the 2 vent fields exceeding 100 individuals per generation. Using the mitochondrial COI gene from juveniles and adults from Broken Spur, TAG and Snake Pit, Shank et al. (1998) came to the same conclusion that the different individuals analyzed were conspecific. Several studies using mtDNA haplotypes (Teixeira et al. 2011), different mitochondrial marker genes (COI, Dong et al. 2019; COI and CytB, Petersen et al. 2010) and microsatellites (Teixeira et al. 2012) of shrimp from 6 sites along the MAR (between $36^{\circ} 16^{\prime} \mathrm{N}$ and $9^{\circ} 33^{\prime} \mathrm{S}$ ) showed an overall high genetic haplotype diversity within the populations, but a lack of strict genetic structure among the different populations. Results also revealed no genetic differentiation among samples separated by up to $11 \mathrm{yr}$ for 2 vent sites (Logatchev and Rainbow). Teixeira et al. $(2011,2012)$ 
suggested that such a pattern could be explained by a recent (about $250 \mathrm{Kyr}$ ago) common bottleneck or (re)colonization event of $R$. exoculata populations along the MAR, followed by an ongoing population extension, with a large panmixia and a probably high larval dispersal capacity (see Section 4.4).

All of these results indicate that neither the distance between vent fields (up to 1000s of km, Vrijenhoek 2010), nor the broad range of depths (2300-4040 m) and the occurrence of the different transform faults or fracture zones along the MAR are obstacles to dispersal and gene flow between the studied $R$. exoculata populations. Teixeira et al. (2012) even reported that of all the species studied to date on hydrothermal vent habitats, $R$. exoculata was the first to exhibit no barriers to dispersal across such a large geographic extent.

\subsection{Symbiont biogeography}

\subsubsection{Branchial chamber symbionts}

In contrast with their hosts, a phylogenetic analyses of the 16S rRNA gene of $R$. exoculata branchial chamber epibionts from 3 vent sites (Rainbow, Logatchev and South MAR) showed spatial clustering of bacterial sequences. This genetic differentiation is correlated with geographic distances between the sites rather than with vent geochemistry (i.e. ultramafic- vs. basalt-hosted vent fields) (Petersen et al. 2010). The authors proposed 2 hypotheses to explain the spatial structuring of symbiont communities, without being able to favor one or the other, due to limited data on free-living relatives of the shrimp symbionts: (1) free-living symbiont communities are genetically isolated due to the existence of barriers to gene flow between vent fields, and the spatial structuring of symbiont communities reflects the diversity of free-living forms of the symbionts; (2) the free-living symbiont communities are not spatially structured along the MAR, and the structuring of symbiont communities at each vent site reflects a specific colonization of the hosts by their symbionts from the pool of diverse free-living forms. Using lux genes, Le Bloa et al. (2017) also showed a geographical clustering of the epibionts according to their vent site origins (Rainbow, TAG, Snake Pit and Logatchev).

Geographical segregation of the symbionts (absent in hosts) may be attributable either to the influence of the environment on symbionts or to the very recent common history of $R$. exoculata populations, with re- cent divergence genetically detectable only in shortgeneration symbionts and still undetectable in the genetics of their hosts (Teixeira et al. 2011).

\subsubsection{Gut symbionts}

As for the branchial chamber symbionts, Campylobacteria and Gammaproteobacteria gut symbionts showed differentiation according to the sampled site (Durand et al. 2015, Cowart et al. 2017). This was interpreted as a local acquisition and or selection to confer better fitness to the holobiont best adapted to the local geochemical environment. In contrast, Deferribacteres and Mollicutes phyla, that have not yet been retrieved in the environment (seawater and chimney samples, Flores et al. 2011, Durand et al. 2015), showed a pattern of phylogenetic differentiation very similar to that of the host, revealing no clear geographical differentiation among the TAG, Logatchev and Ashadze sites. These results are interpreted, for hosts and these symbionts, as significant recurrent gene flow and/or a recent and common bottleneck-expansion history across MAR sites (Teixeira et al. 2011, 2012). This would also be in favor of a vertical transmission for these symbiont lineages (Durand et al. 2015, Cowart et al. 2017). The epibiont divergence pattern at the ribotype level contrasted with that of the hosts only at the Rainbow site (Durand et al. 2015). Both physical (the shallower depth compared to the other sites and its peculiar position at the intersection between the nontransform fault system and the ridge fault; Charlou et al. 2010), as well as the unique geochemical conditions prevailing at Rainbow, could be a factor affecting selective pressures acting on epibionts (Durand et al. 2015). Durand et al. (2015) proposed that the observed epibiont biogeography would reflect an ongoing MAR colonization from the north to the south.

\section{KEY FEATURES OF SHRIMP ECOLOGY, POTENTIAL THREATS AND RESILIENCE}

The shrimp Rimicaris exoculata represents the dominant faunal biomass at many deep-sea hydrothermal vent ecosystems along the MAR, and can be regarded as a keystone species on the MAR hydrothermal vents. Key ecological features of the species are summarized in Fig. 10. The knowledge of the requirements and range of tolerance of $R$. exoculata would help to predict how this species will respond to specific environmental changes. Steep modifi- 


\section{Rimicaris exoulata Identity Card}

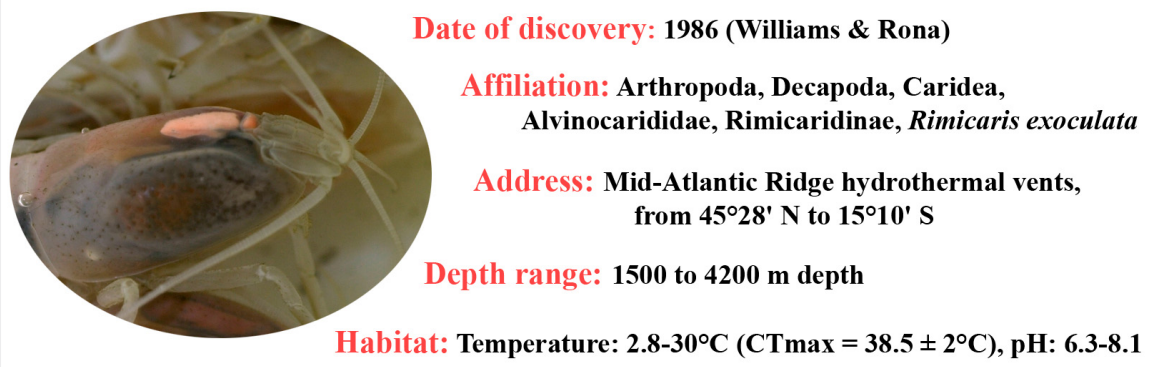

Physical features: Highly inflated cephalothorax, dorsal visual organ

Trophic status: Primary consumer, gaining its carbon from its cephalothoracic symbionts, through transtegumental absorption of bacterial products

Perception: Perception of dim lights through highly modified eyes, detection of sulfides through antennae and antennules, significant role of place memory

Reproduction: Seasonal

Known predators: S. mesatlantica, Phymorhynchus sp., actinarians, bathyal fishes, $R$. chacei

Actual major gaps in the shrimp ecology, biology and physiology:

Symbiosis: exchange of molecules and recognition / communication between host and symbionts;

Life cycle: attraction behaviour, partner recognition, copulation, larval dispersal and lifespan, recruitment cues;

Lifespan; Existence of social interactions

Fig. 10. Rimicaris exoculata identity card cations, whether of natural (tectonic event, volcanic eruption) or anthropogenic origin (global warming, ocean acidification, mining) can impact hydrothermal ecosystems. Although difficult to reach because of their depth and globally less affected than coastal or terrestrial ecosystems, deep-sea hydrothermal vents are under a growing threat because of the strategic metals and minerals they contain (Van Dover 2011, Miller et al. 2018). Despite 40 yr of scientific investigations, our knowledge of the resilience of these ecosystems (i.e. the ability to cope with the modifications and to rebuild after disturbances) is still too incomplete to assess the risks associated with this activity, or to predict the impacts of a possible exploitation. There are still too many crucial gaps regarding biodiversity or functioning of hydrothermal ecosystems (Boschen et al. 2013, Orcutt et al. 2020).

Mining procedures in the deep sea are still in their infancy, so it is difficult to predict if mining rejections would occur at the surface, in the water column or on the sea bottom. If close to hydrothermal sites, the mining rejections in the water could impact vent communities, first, through the appearance of microbial blooms that would use these mineral wastes. That would modify the microbial diversity and thus potentially affect the entire food chain that depends on it, as well as the horizontally transmitted symbiotic associations, such as observed in $R$. exoculata.
Second, mineral deposition on faunistic assemblages could result in niche destruction, or aberrant recruitment signals compromising colonization by juveniles. $R$. exoculata is a keystone species, living in symbiosis with 2 symbiotic communities, which dominates and probably shapes the faunal assemblages of the sites that it colonizes. Impacts on shrimp aggregations could destabilize the entire faunal assemblages and thus also strongly impact all other species. Even if $R$. exoculata does not, at first glance, meet the criteria to be considered a vulnerable species because of its life traits (high population density, high reproduction, significant migration capacity), its patchy habitat is nonetheless likely to be impacted by exploitation mining, thereby putting the shrimp itself at risk. Since little is currently known about the source-sink dynamics of $R$. exoculata between sites, the metapopulation stability or the resilience of the shrimp, it is difficult to assess the consequences of the destruction of one or more sites hosting this species on the long-term persistence of the species at hydrothermal sites. Apart from their ecological and cultural value, isolated ecosystems house a huge and unpredictable genetic reservoir, with potential new industrial, biotechnological and medical applications. Filling the many gaps in our knowledge of the biology and ecology of this major species of the MAR is therefore more important than ever to establish appropriate conservation strategies for these ecosystems. 


\section{PERSPECTIVES}

Our knowledge of Rimicaris exoculata ecology has increased greatly since its first description (Williams \& Rona 1986). However, studies on hydrothermal fauna have long remained, and still are, limited due to the remoteness of the sites, the difficulty to perform in vivo experiments on animals shocked by decompression during ascent to the surface, as well as the low frequency of cruises, usually scheduled during spring/summer due to weather conditions. These impediments are now overcome by the development of pressurized equipment, which allows recovery (Shillito et al. 2008) and maintenance (Shillito et al. 2014) of faunal species at native pressure to tackle physiological issues by in vivo experiments on animals in good physiological condition. Furthermore, long-term rearing of some deep-sea fauna is now possible thanks to aquariums like the 'AbyssBox,' which allows studies of species interactions and behavior, sensorial adaptations, reproduction and larval development (Shillito et al. 2015). From an ecological point of view, studies on deep-sea currents, habitat description and population distribution at a finer scale, as well as $R$. exoculata biotic interactions with other hydrothermal species are needed. For symbiotic species, such as $R$. exoculata and its endosymbionts, a gap is still to be filled regarding our ability to reproduce in situ life conditions in pressurized aquaria to allow the study of symbiosis dynamics. An integrated study of the holobiont (i.e. both the symbionts and host) genome metatranscriptome and metaproteome (as done on the siboglinid Paraescarpia echinospica, Yang et al. 2020) would provide important information on host and symbionts (inter)dependence on nutrient provisions and how they regulate each other to maintain a stable symbiotic relationship. For example, in recent years, cruises scheduled outside summer months allowed sampling during the shrimp breeding season, providing precious samples of the first eggs and early larval stages. Nevertheless, larval dispersal remains a clear knowledge gap to fully understand the ecology of this holobiont and its colonization success in so many vent sites along the MAR.

In the future, technological developments will undoubtedly help to answer the still unresolved questions about the biology and physiology of this shrimp, such as the regulation of the different metabolic pathways within the epibiosis according to the harvested site and the possible synthrophy between symbiont lineages; the nature of the molecules exchanged between symbionts and hosts; the establishment of symbiosis and host-symbiont recognition/communication mechanisms; the life span of shrimp and their full life cycle or the way these shrimp locate in their environment and communicate with each other. This holobiont is one of the dominant species along the MAR, showing an apparent huge potential of dispersion and adaptation. In the frame of the mining licenses implying a threat to deep-sea environments, this species is a model still to be studied to better understand life in extreme deep-sea ecosystems at the global scale of an ocean.

Acknowledgements. We thank the chief scientists of the numerous cruises, as well as captains and crews of the research vessels and the submersibles for their invaluable assistance in providing Rimicaris exoculata samples. We thank B. Shillito, J. Ravaux, J. Sarrazin, F. Pradillon and F. Lallier for their contributions to this manuscript. This work was supported in part by UPMC Sorbonne Universités, Ifremer REMIMA Program and Region Bretagne, and indirectly by the following grants: the European Union Seventh Framework Programme (FP7/2007-2013) under the MIDAS project [grant agreement no. 603418] and the National program BALIST ANR-08-BLAN-0252, the Carnot program and LabexMer.

\section{LITERATURE CITED}

Ache B (1982) Chemoreception and thermoreception. In: Bliss D (ed) The biology of Crustacea, Vol 3. Academic Press, New York, NY, p 369-398

Allen C, Copley J, Tyler P (2001) Lipid partitioning in the hydrothermal vent shrimp Rimicaris exoculata. Mar Ecol 22:241-253

Allen-Copley C, Tyler P, Varney M (1998) Lipid profiles of hydrothermal vent shrimps. Cah Biol Mar 39:229-231

* Anderson L, Halary S, Lechaire JP, Boudier T and others (2008) Tomography of bacteria-mineral associations within the deep sea hydrothermal vent shrimp Rimicaris exoculata. C R Chim 11:268-280

Ansorge R, Romano S, Sayavedra L, González Porras MÁ and others (2019) Functional diversity enables multiple symbiont strains to coexist in deep-sea mussels. Nat Microbiol 4:2487-2497

Apremont V, Cambon-Bonavita MA, Cueff-Gauchard V, François D, Pradillon F, Corbari L, Zbinden M (2018) Gill chamber and gut microbial communities of the hydrothermal shrimp Rimicaris chacei Williams and Rona 1986: a possible symbiosis. PLOS ONE 13:e0206084

Arp AJ, Childress JJ (1981) Functional characteristics of the blood of the deep-sea hydrothermal vent brachyuran crab. Science 214:559-561

Assié A, Leisch N, Meier DV, Gruber-Vodicka H and others (2020) Horizontal acquisition of a patchwork Calvin cycle by symbiotic and free-living Campylobacterota (formerly Epsilonproteobacteria). ISME J 14:104-122

Auguste M, Mestre NC, Rocha TL, Cardoso C and others (2016) Development of an ecotoxicological protocol for the deep-sea fauna using the hydrothermal vent shrimp Rimicaris exoculata. Aquat Toxicol 175:277-285 
Bachraty C, Legendre P, Desbruyères D (2009) Biogeographic relationships among deep-sea hydrothermal vent faunas at global scale. Deep Sea Res I 56:1371-1378

Baker ET, Resing JA, Haymon RM, Tunnicliffe V and others (2016) How many vent fields? New estimates of vent field populations on ocean ridges from precise mapping of hydrothermal discharge locations. Earth Planet Sci Lett 449:186-196

Bates AE, Lee RW, Tunnicliffe V, Lamare MD (2010) Deepsea hydrothermal vent animals seek cool fluids in a highly variable thermal environment. Nat Commun 1:14

Bauer R (1989) Decapod crustaceans grooming: functional morphology, adaptive value, and phylogenetic significance. In: Felgenhauer B, Watling L, Thistle A (eds) Functional morphology of feeding and grooming in Crustacea. AA Balkema, Rotterdam, p 49-73

Beinart RA, Sanders JG, Faure B, Sylva SP and others (2012) Evidence for the role of endosymbionts in regional-scale habitat partitioning by hydrothermal vent symbioses. Proc Natl Acad Sci USA 109:E3241-E3250

Boschen RE, Rowden AA, Clark MR, Gardner JPA (2013) Mining of deep-sea seafloor massive sulfides: A review of the deposits, their benthic communities, impacts from mining, regulatory frameworks and management strategies. Ocean Coast Manage 84:54-67

Bridges CR, Morris S, Grieshaber MK (1984) Modulation of haemocyanin oxygen affinity in the intertidal prawn Palaemon elegans (Rathke). Respir Physiol 57:189-200

Bright M, Bulgheresi S (2010) A complex journey: transmission of microbial symbionts. Nat Rev Microbiol 8: 218-230

Bulgheresi S, Schabussova I, Chen T, Mullin N, Maizels R, Ott J (2006) A new C-type lectin similar to the human immunoreceptor DC-SIGN mediates symbiont acquisition by a marine nematode. Appl Environ Microbiol 72: 2950-2956

Campbell BJ, Cary SC (2004) Abundance of reverse tricarboxylic acid cycle genes in free-living microorganisms at deep-sea hydrothermal vents. Appl Environ Microbiol 70:6282-6289

Casanova B, Brunet M, Segonzac M (1993) L'impact d'une épibiose bactérienne sur la morphologie fonctionnelle de crevettes associées à l'hydrothermalisme médio-Atlantique. Cah Biol Mar 34:573-588

Cate HS, Derby CD (2001) Morphology and distribution of setae on the antennules of the Caribbean spiny lobster Panulirus argus reveal new types of bimodal chemomechanosensilla. Cell Tissue Res 304:439-454

Chamberlain SC (2000) Vision in hydrothermal vent shrimp. Philos Trans R Soc B 355:1151-1154

* Charlou JL, Donval JP, Fouquet Y, Jean-Baptiste P, Holm N, Caccavo $\mathrm{F}$ (2002) Geochemistry of high $\mathrm{H}_{2}$ and $\mathrm{CH}_{4}$ vent fluids issuing from ultramafic rocks at the Rainbow hydrothermal field $\left(36^{\circ} 14^{\prime} \mathrm{N}, \mathrm{MAR}\right)$. Chem Geol 191: 345-359

Charlou J, Donval J, Konn C, Ondréas H, Fouquet Y, JeanBaptiste P, Fourré E (2010) High production and fluxes of $\mathrm{H}_{2}$ and $\mathrm{CH}_{4}$ and evidence of abiotic hydrocarbon synthesis by serpentinization in ultramafic-hosted hydrothermal systems on the Mid-Atlantic Ridge. In: Rona P, Devey C, Dyment J, Murton B (eds) Diversity of hydrothermal systems on slow spreading ocean ridges. American Geophysical Union, Washington, DC, p 265-296

Chausson F, Bridges CR, Sarradin PM, Green BN, Riso R, Caprais JC, Lallier FH (2001) Structural and functional properties of hemocyanin from Cyanagraea praedator, a deep-sea hydrothermal vent crab. Proteins 45:351-359

* Chausson F, Sanglier S, Leize E, Hagège A and others (2004) Respiratory adaptations to the deep-sea hydrothermal vent environment: the case of Segonsacia mesatlantica, a crab from the Mid-Atlantic Ridge. Micron 35:31-41

Childress J, Fisher C (1992) The biology of hydrothermal vent animals: physiology, biochemistry and autotrophic symbioses. Oceanogr Mar Biol Annu Rev 30:337-441

Christoffersen ML (1986) Phylogenetic relationships between Oplophoridae, Atyidae, Pasiphaeidae, Alvinocarididae fam. n., Bresiliidae, Psalidopodidae and Disciadidae (Crustacea Caridea Atyoidea). Bol Zool Univ Sao Paolo 10:273-281

* Colaço A, Dehairs F, Desbruyères D (2002) Nutritional relations of deep-sea hydrothermal fields at the Mid-Atlantic Ridge: a stable isotope approach. Deep Sea Res I 49: 395-412

Compère $\mathrm{P}$, Martinez A, Charmantier-Daures M, Toullec J, Goffinet G, Gaill F (2002) Does sulphide detoxication occur in the gills of the hydrothermal vent shrimp, Rimicaris exoculata? C R Biol 325:591-596

* Copley JTP, Young CM (2006) Seasonality and zonation in the reproductive biology and population structure of the shrimp Alvinocaris stactophila (Caridea: Alvinocarididae) at a Louisiana Slope cold seep. Mar Ecol Prog Ser 315:199-209

Copley J, Tyler P, Murton B, Van Dover C (1997) Spatial and interannual variation in the faunal distribution at Broken Spur vent field $\left(29^{\circ} \mathrm{N}\right.$, Mid-Atlantic Ridge). Mar Biol 129: 723-733

Copley J, Jorgensen P, Sohn R (2007) Assessment of decadal-scale ecological change at a deep Mid-Atlantic hydrothermal vent and reproductive time-series in the shrimp Rimicaris exoculata. J Mar Biol Assoc UK 87: 859-867

Corbari L, Zbinden M, Cambon-Bonavita MA, Gaill F, Compère $P(2008 a)$ Bacterial symbionts and mineral deposits in the branchial chamber of the hydrothermal vent shrimp Rimicaris exoculata: relationship to moult cycle. Aquat Biol 1:225-238

* Corbari L, Cambon-Bonavita MA, Long GJ, Grandjean F, Zbinden M, Gaill F, Compère P (2008b) Iron oxide deposits associated with the ectosymbiotic bacteria in the hydrothermal vent shrimp Rimicaris exoculata. Biogeosciences 5:1295-1310

* Corliss JB, Dymond J, Gordon LI, Edmond JM and others (1979) Submarine thermal springs on the Galápagos Rift. Science 203:1073-1083

* Correa C, Thiel M (2003) Mating systems in caridean shrimp (Decapoda: Caridea) and their evolutionary consequences for sexual dimorphism and reproductive biology. Rev Chil Hist Nat 76:187-203

Cosson-Mannevy MA, Cosson RP, Gaill F, Laubier L (1988) Transfert, accumulation et régulation des éléments minéraux chez les organismes des sources hydrothermales. Oceanol Acta (Spec Issue):219-226

* Cottin D, Shillito B, Chertemps T, Thatje S, Léger N, Ravaux $\mathrm{J}$ (2010a) Comparison of heat-shock responses between the hot vent shrimp Rimicaris exoculata and the related coastal shrimp Palaemonetes varians. J Exp Biol 393: 9-16

Cottin D, Shillito B, Tanguy A, Léger N, Ravaux J (2010b) Identification of differentially expressed genes in the hydrothermal vent shrimp Rimicaris exoculata exposed 
to heat stress. Mar Genomics 3:71-78

Cowart D, Durand L, Cambon-Bonavita MA, Arnaud-Haon S (2017) Investigation of bacterial communities within the digestive organs of the hydrothermal vent shrimp Rimicaris exoculata provide insights into holobiont geographic clustering. PLOS ONE 12:e0172543

Creasey S, Rogers A, Tyler P (1996) Genetic comparison of two populations of the deep-sea vent shrimp Rimicaris exoculata (Decapoda: Bresiliidae) from the Mid-Atlantic Ridge. Mar Biol 125:473-482

Crone TJ, Wilcock WSD, Barclay AH, Parsons JD (2006) The sound generated by mid-ocean ridge black smoker hydrothermal vents. PLOS ONE 1:e133

Cuomo MC (1985) Sulphide as a larval settlement cue for Capitella sp I. Biogeochemistry 1:169-181

Demina LL, Holm NG, Galkin SV, Lein AY (2013) Some features of the trace metal biogeochemistry in the deep-sea hydrothermal vent fields (Menez Gwen, Rainbow, Broken Spur at the MAR and $9^{\circ} 50^{\prime} \mathrm{N}$ at the EPR): a synthesis. J Mar Syst 126:94-105

Derby C, Weissburg M (2014) The chemical senses and chemosensory ecology of crustaceans. In: Derby C, Thiel $M$ (eds) Nervous systems and control behavior. The natural history of the Crustacea, Vol 3. Oxford University Press, New York, NY, p 263-292

Derby CD, Kozma MT, Senatore A, Schmidt M (2016) Molecular mechanisms of reception and perireception in crustacean chemoreception: a comparative review. Chem Senses 41:381-398

* Desbruyères D, Almeida A, Biscoito $M$, Comtet $T$ and others (2000) A review of the distribution of hydrothermal vent communities along the northern Mid-Atlantic Ridge: dispersal vs. environmental controls. Hydrobiologia 440: 201-216

* Desbruyères D, Biscoito M, Caprais JC, Colaço A and others (2001) Variations in deep-sea hydrothermal vent communities on the Mid-Atlantic Ridge near the Azores plateau. Deep Sea Res I 48:1325-1346

Desbruyères D, Segonzac M, Bright M (2006) Handbook of deep-sea hydrothermal vent fauna, $2^{\text {nd }}$ compl rev edn. Denisia, Vol 18. Biologiezentrum, Linz

* Distel DL, Lane DJ, Olsen GJ, Giovannoni SJ and others (1988) Sulfur-oxidizing bacterial endosymbionts: analysis of phylogeny and specificity by $16 \mathrm{~S}$ rRNA sequences. J Bacteriol 170:2506-2510

Dixon DR, Dixon L, Pond DW (1998) Recent advances in our understanding of the life history of bresiliid vent shrimps on the MAR. Cah Biol Mar 39:383-386

Dong C, Xie Y, Li H, Lai Q, Liu X, Shao Z (2019) Faunal and microbial biodiversity of the newly discovered Deyin-1 hydrothermal vent field at $15^{\circ} \mathrm{S}$ on the southern MidAtlantic Ridge. Deep Sea Res I 153:103134

Douville E, Charlou JL, Oelkers EH, Bienvenu P and others (2002) The Rainbow vent fluids $\left(36^{\circ} 14^{\prime} \mathrm{N}, \mathrm{MAR}\right)$ : the influence of ultramafic rocks and phase separation on trace metal content in Mid-Atlantic Ridge hydrothermal fluids. Chem Geol 184:37-48

Drach P, Tchernigovtzeff C (1967) Sur la méthode de détermination des stages d'intermue et son application générale aux Crustacés. Vie Milieu 18A:595-609

Duperron S, Halary S, Lorion J, Sibuet M, Gaill F (2008) Unexpected co-occurrence of six bacterial symbionts in the gills of the cold seep mussel Idas sp. (Bivalvia: Mytilidae). Environ Microbiol 10:433-445

* Durand L, Zbinden M, Duperron S, Roussel E, Cueff-
Gauchard V, Shillito B, Cambon-Bonavita MA (2010) Microbial diversity associated with the hydrothermal vent shrimp Rimicaris exoculata gut and occurrence of a resident microbial community. FEMS Microbiol Ecol 71: 291-303

* Durand L, Roumagnac M, Cueff-Gauchard V, Jan C and others (2015) Biogeographical distribution of Rimicaris exoculata resident gut epibiont communities along the Mid-Atlantic Ridge hydrothermal vent sites. FEMS Microbiol Ecol 91:fiv101

Emerson D, Moyer C (1997) Isolation and characterization of novel iron-oxidizing bacteria that grow at circumneutral pH. Appl Environ Microbiol 63:4784-4792

*Emerson D, Rentz JA, Lilburn TG, Davis RE, Aldrich H, Chan C, Moyer CL (2007) A novel lineage of Proteobacteria involved in formation of marine Fe-oxidizing microbial mat communities. PLOS ONE 2(8):e667

*Fisher CR, Childress JJ, Minnich E (1989) Autotrophic carbon fixation by the chemoautotrophic symbionts of Riftia pachyptila. Biol Bull (Woods Hole) 177:372-385

Flores GE, Campbell JH, Kirshtein JD, Meneghin J and others (2011) Microbial community structure of hydrothermal deposits from geochemically different vent fields along the Mid-Atlantic Ridge. Environ Microbiol 13:2158-2171

Fouquet Y, Cherkashov G, Charlou J, Ondréas H and others (2008) Serpentine cruise - ultramafic hosted hydrothermal deposits on the Mid-Atlantic Ridge: first submersible studies on Ashadze 1 and 2, Logatchev 2 and Krasnov vent fields. InterRidge News 17:16-21

Fouquet Y, Cambon P, Etoubleau J, Charlou J and others (2010) Geodiversity of hydrothermal processes along the Mid-Atlantic Ridge and ultramafic-hosted mineralization: a new type of oceanic $\mathrm{Cu}-\mathrm{Zn}-\mathrm{Co}-\mathrm{Au}$ volcanogenic massive sulfide deposit. In: Rona P, Devey C, Dyment J, Murton B (eds) Diversity of hydrothermal systems on slow spreading ocean ridges. Geophysical Monograph Series, Vol 188. American Geophysical Union, Washington, DC, p 321-267

Gaill F, Desbruyères D, Prieur D, Gourret J (1984) Mise en évidence de communautés bactériennes épibiontes vu 'Ver de Pompéí' (Alvinella pompejana). C R Acad Sci III 298:553-558

Gaten E, Herring P, Shelton P, Johnson M (1998a) Comparative morphology of the eyes of postlarval bresiliid shrimps from the region of hydrothermal vents. Biol Bull (Woods Hole) 194:267-280

Gaten E, Herring P, Shelton P, Johnson M (1998b) The development and evolution of the eyes of vent shrimps (Decapoda: Bresiliidae). Cah Biol Mar 39:287-290

KGebruk AV, Pimenov NV, Savvichev AS (1993) Feeding specialization of bresiliid shrimps in the TAG site hydrothermal community. Mar Ecol Prog Ser 98:247-253

* Gebruk A, Galkin S, Vereshchaka A, Moskalev L, Southward A (1997a) Ecology and biogeography of the hydrothermal vent fauna of the Mid-Atlantic Ridge. Adv Mar Biol 32:93-144

Gebruk A, Lein A, Galkin S, Miller Y, Pimenov N, Moskalev L, Ivanov M (1997b) Trophic structure of the Broken Spur hydrothermal community shown by carbon stable isotope and C:H:N:S data. BRIDGE Newsl 12:40-45

Gebruk A, Southward E, Kennedy H, Southward A (2000) Food sources, behaviour, and distribution of hydrothermal vent shrimp at the Mid-Atlantic Ridge. J Mar Biol Assoc UK 80:485-499 
Geret F, Riso R, Sarradin PM, Caprais JC, Cosson R (2002) Metal bioaccumulation and storage forms in the shrimp, Rimicaris exoculata, from the Rainbow hydrothermal field (Mid-Atlantic Ridge); preliminary approach to the fluid-organism relationship. Cah Biol Mar 43:43-52

Gloter A, Zbinden M, Guyot F, Gaill F, Colliex C (2004) Formation and stabilization of mixed valence ferrihydrite on bacterial surfaces from hydrothermal vents. Earth Planet Sci Lett 222:947-957

Gonzalez-Rey M, Serafim A, Company R, Bebianno M (2007) Adaptation to metal toxicity: a comparison of hydrothermal vent and coastal shrimps. Mar Ecol 28:100-107

Gonzalez-Rey M, Serafim A, Company R, Gomes T, Bebianno M (2008) Detoxification mechanisms in shrimp: comparative approach between hydrothermal vent fields and estuarine environments. Mar Environ Res 66:35-37

Gourdine JP, Markiv A, Smith-Ravin J (2007) The threedimensional structure of codakine and related marine Ctype lectins. Fish Shellfish Immunol 23:831-839

Gramling C (2014) Seafloor mining plan advances, worrying critics. Science 344:463

* Grünert U, Ache BW (1988) Ultrastructure of the aesthetasc (olfactory) sensilla of the spiny lobster, Panulirus argus. Cell Tissue Res 251:95-103

Gu HJ, Sun QI, Jiang S, Zhang J, Sun L (2018) First characterization of an anti-lipopolysaccharide factor (ALF) from hydrothermal vent shrimp: insights into the immune function of deep-sea crustacean ALF. Dev Comp Immunol 84: 382-395

Guri M, Durand L, Cueff-Gauchard V, Zbinden M, Crassous P, Shillito B, Cambon-Bonavita MA (2012) Acquisition of epibiotic bacteria along the life cycle of the hydrothermal shrimp Rimicaris exoculata. ISME J 6:597-609

Haase KM, Petersen S, Koschinsky A, Seifert R and others (2007) Young volcanism and related hydrothermal activity at $5^{\circ} \mathrm{S}$ on the slow-spreading southern Mid-Atlantic Ridge. Geochem Geophys Geosyst 8:Q11002

Henri PA, Rommevaux-Jestin C, Lesongeur F, Mumford A, Emerson D, Godfroy A, Ménez B (2016) Structural Iron (II) of basaltic glass as an energy source for Zetaproteobacteria in an abyssal plain environment, off the Mid Atlantic Ridge. Front Microbiol 6:1518

Hernandez-Avila I (2016) Larval dispersal and life cycle in deep-water hydrothermal vents: the case of Rimicaris exoculata and related species. PhD thesis, Université de Bretagne Occidentale, Brest

* Hernandez-Avila I, Cambon-Bonavita MA, Pradillon F (2015) Morphology of first zoeal stage of four genera of alvinocaridid shrimps from hydrothermal vents and cold seeps: implications for ecology, larval biology and phylogeny. PLOS ONE 10:e0144657

KHerring PJ (1998) North Atlantic midwater distribution of the juvenile stages of hydrothermal vent shrimps (Decapoda: Bresiliidae). Cah Biol Mar 39:387-390

Herring PJ, Dixon DR (1998) Extensive deep-sea dispersal of postlarval shrimp from a hydrothermal vent. Deep Sea Res I 45:2105-2118

Herring PJ, Gaten E, Shelton PMJ (1999) Are the shrimp blinded by science? Nature 398:116

*Hourdez S, Lallier F (2007) Adaptations to hypoxia in hydrothermal-vent and cold-seep invertebrates. Rev Environ Sci Biotechnol 6:143-159

Hügler M, Gärtner A, Imhoff JF (2010) Functional genes as markers for sulfur cycling and $\mathrm{CO}_{2}$ fixation in microbial communities of hydrothermal vents of the Logatchev field. FEMS Microbiol Ecol 73:526-537

*Hügler M, Wirsen C, Fuchs S, Taylor C, Sievert S (2005) Evidence for autotrophic $\mathrm{CO}_{2}$ fixation via the reductive tricarboxylic acid cycle by members of the epsilon subdivision of Proteobacteria. J Bacteriol 187:3020-3027

Hügler M, Petersen J, Dubilier N, Imhoff J, Sievert S (2011) Pathways of carbon and energy metabolism of the epibiotic community associated with the deep-sea hydrothermal vent shrimp Rimicaris exoculata. PLOS ONE 6: e16018

Jan C, Petersen JM, Werner J, Teeling H and others (2014) The gill chamber epibiosis of deep-sea shrimp Rimicaris exoculata: an in-depth metagenomic investigation and discovery of Zetaproteobacteria. Environ Microbiol 16: 2723-2738

Jannasch H, Wirsen C (1979) Chemosynthetic primary production at east Pacific sea floor spreading centers. Bioscience 29:592-98

Jiang L, Liu X, Dong C, Huang Z and others (2020) 'Candidatus Desulfobulbus rimicarensis,' an uncultivated deltaproteobacterial epibiont from the deep-sea hydrothermal vent shrimp Rimicaris exoculata. Appl Environ Microbiol 86:e02549-19

Jinks R, Battelle B, Herzog E, Kass L, Renninger G, Chamberlain $S$ (1998) Sensory adaptations in hydrothermal vent shrimps from the Mid-Atlantic Ridge. Cah Biol Mar 39:309-312

* Jinks RN, Markley TL, Taylor EE, Perovich G, Dittel AI, Epifanio CE, Cronin TW (2002) Adaptative visual metamorphosis in a deep-sea hydrothermal crab. Nature 420: $68-70$

Jones JC, Oldroy BP (2006) Nest thermoregulation in social insects. Adv Insect Physiol 33:153-191

Kádár E, Costa V, Santos RS (2006) Distribution of microessential (Fe, $\mathrm{Cu}, \mathrm{Zn})$ and toxic ( $\mathrm{Hg}$ ) metals in tissues of two nutritionally distinct hydrothermal shrimps. Sci Total Environ 358:143-150

Kennedy C, Scott S, Ferris F (2004) Hydrothermal phase stabilization of 2-line ferrihydrite by bacteria. Chem Geol 212:269-277

Komai T, Giguère T (2019) A new species of alvinocaridid shrimp Rimicaris Williams \& Rona, 1986 (Decapoda: Caridea) from hydrothermal vents on the Mariana Back Arc Spreading Center, northwestern Pacific. J Crustac Biol 39:640-650

Komai T, Segonzac M (2003) Review of the hydrothermal vent shrimp genus Mirocaris, redescription of $M$. fortunata and reassessment of the taxonomic status of the family Alvinocarididae (Crustacea: Decapoda: Caridea). Cah Biol Mar 44:199-215

Komai T, Segonzac M (2008) Taxonomic review of the hydrothermal vent shrimp genera Rimicaris Williams and Rona and Chorocaris Martin and Hessler (Crustacea: Decapoda; Caridea: Alvinocarididae). J Shellfish Res 27: 21-41

Komai T, Tsuchida S (2015) New records of Alvinocarididae (Crustacea: Decapoda: Caridea) from the southwestern Pacific hydrothermal vents, with descriptions of one new genus and three new species. J Nat Hist 49: 1789-1824

Komai T, Giere O, Segonzac M (2007) New record of alvinocarid shrimps (Crustacea: Decapoda: Caridea) from hydrothermal vent fields on the southern Mid-Atlantic Ridge, including a new species of the genus Opaepele. Species Divers 12:237-253 
Kornberg A (1995) Inorganic polyphosphate: toward making a forgotten polymer unforgettable. J Bacteriol 177: 491-496

Koyama S, Nagahama T, Ootsu N, Takayama T and others (2005) Survival of deep-sea shrimp (Alvinocaris sp.) during decompression and larval hatching at atmospheric pressure. Mar Biotechnol 7:272-278

Kuenzler RO, Kwasniewski JT, Jinks RN, Lakin RC and others (1997) Retinal anatomy of new bresiliid shrimp from Lucky Strike and Broken Spur hydrothermal vent fields on the Mid-Atlantic Ridge. J Mar Biol Assoc UK 77 : $707-725$

Lakin RC, Jinks RN, Battelle BA, Herzog ED, Kass L, Renninger GH, Chamberlain SC (1997) Retinal anatomy of Chorocaris chacei, a deep-sea hydrothermal vent shrimp from the Mid-Atlantic Ridge. J Comp Neurol 385:503-514

Lallier F, Truchot J (1997) Hemocyanin oxygen-binding properties of a deep-sea hydrothermal vent shrimpevidence for a novel cofactor. J Exp Biol 277:357-364

Lallier F, Camus L, Chausson F, Truchot J (1998) Structure and function of hydrothermal vent crustacean haemocyanin: an update. Cah Biol Mar 39:313-316

Larsen E, Quétel C, Munoz R, Fiala-Médioni A, Donard O (1997) Arsenic speciation in shrimp and mussel from the Mid-Atlantic hydrothermal vents. Mar Chem 57:341-346

Laverack MS (1964) The antennular sense organs of Panulirus argus. Comp Biochem Physiol 13:301-321

Le Bloa S, Durand L, Taupin L, Marteau C, Cueff-Gauchard V, Bazire A, Cambon-Bonavita MA (2017) Highlighting of quorum sensing lux genes and their expression in the hydrothermal vent shrimp Rimicaris exoculata ectosymbiontic community. Possible use as markers of biogeography. PLOS ONE 12:e0174338

Le Bloa S, Boidin-Wichlacz C, Cueff-Gauchard V, Rosa R and others (2020) Antimicrobial peptides and ectosymbiotic relationships: involvement of a novel Type IIa crustin in the life cycle of a deep-sea vent shrimp. Front Immunol 11:1511

KLiu XL, Ye S, Cheng CY, Li HW, Lu B, Yang WJ, Yang JS (2019) Identification and characterization of a symbiotic agglutination-related C-type lectin from the hydrothermal vent shrimp Rimicaris exoculata. Fish Shellfish Immunol 92:1-10

Lonsdale P (1977) Clustering of suspension-feeding macrobenthos near abyssal hydrothermal vents at oceanic spreading centers. Deep-Sea Res 24:857-863

* Machon J, Lucas P, Ravaux J, Zbinden M (2018) Comparison of chemoreceptive abilities of the hydrothermal shrimp Mirocaris fortunata and the coastal shrimp Palaemon elegans. Chem Senses 43:489-501

Machon J, Krieger J, Meth R, Ravaux J, Zbinden M, Harzsch S (2019) Brain architecture of the hydrothermal vent shrimp Rimicaris exoculata (Malacostraca: Caridea): adaptions to an extreme deep sea environment. eLife 8: e47550

Markert S, Arndt C, Felbeck H, Becher D and others (2007) Physiological proteomics of the uncultured endosymbiont of Riftia pachyptila. Science 315:247-250

Martin J, Haney T (2005) Decapod crustaceans from hydrothermal vents and cold seeps: a review through 2005. Zool J Linn Soc 145:445-522

Martin J, Hessler R (1990) Chorocaris vandoverae, a new genus and species of hydrothermal vent shrimp (Crustacea, Decapoda, Bresiliidae) from the Western Pacific. Contrib Sci 417:1-11
Martin J, Shank T (2005) A new species of the shrimp genus Chorocaris (Decapoda: Caridea: Alvinocarididae) from hydrothermal vents in the eastern Pacific Ocean. Proc Biol Soc Wash 118:183-198

Martin J, Signorovitch J, Patel H (1997) A new species of Rimicaris (Crustacea: Decapoda: Bresiliidae) from the Snake Pit hydrothermal vent field on the Mid-Atlantic Ridge. Proc Biol Soc Wash 110:399-411

* Martinez AS, Charmantier G, Compère P, CharmantierDaures M (2005) Branchial chamber tissues in two caridean shrimps: the epibenthic Palaemon adspersus and the deep-sea hydrothermal Rimicaris exoculata. Tissue Cell 37:153-165

*Martins I, Porteiro F, Cravo A, Santos R (2001) Mercury concentrations in invertebrates from Mid-Atlantic Ridge hydrothermal vent fields. J Mar Biol Assoc UK 81:913-915

* Maza FJ, Sztarker J, Shkedy A, Peszano VN, Locatelli FF, Delorenzi A (2016) Context-dependent memory traces in the crab's mushroom bodies: functional support for a common origin of high-order memory centers. Proc Natl Acad Sci USA 113:E7957

Mellon D (2014) Sensory systems of crustaceans. In: Derby C, Thiel M (eds) Nervous systems and control behavior. The natural history of the Crustacea, Vol 3. Oxford University Press, New York, NY, p 49-84

Mengerink KJ, Van Dover CL, Ardron J, Baker M and others (2014) A call for deep-ocean stewardship. Science 344: 696-698

Methou P, Hernandez-Avila I, Aube J, Cueff-Gauchard V and others (2019) Is it first the egg or the shrimp? Diversity and variation in microbial communities colonizing broods of the vent shrimp Rimicaris exoculata during embryonic development. Front Microbiol 10:808

Methou P, Michel L, Segonzac M, Cambon-Bonavita MA, Pradillon F (2020) Integrative taxonomy revisits the ontogeny and trophic niches of Rimicaris vent shrimps. R Soc Open Sci 7:200837

Miller KA, Thompson KF, Johnston P, Santillo D (2018) An overview of seabed mining including the current state of development, environmental impacts, and knowledge gaps. Front Mar Sci 4:418

* Millero F, Sotolongo S, Izaguirre M (1987) The oxidation kinetics of $\mathrm{Fe}(\mathrm{II})$ in seawater. Geochim Cosmochim Acta 51:793-801

* Moalic Y, Desbruyères D, Duarte C, Rozenfeld A, Bachraty C, Arnaud-Haon S (2012) Biogeography revisited with network theory: retracing the history of hydrothermal vent communities. Syst Biol 61:127-137

Montgomery K, Charlesworth J, LeBard R, Visscher P, Burns B (2013) Quorum sensing in extreme environments. Life 3:131-148

Nelson DC, Fisher CR (1995) Chemoautotrophic and methanotrophic endosymbiotic bacteria at deep-sea vents and seeps. In: Karl DM (ed) The microbiology of deep-sea hydrothermal vents. CRC Press, Boca Raton, FL, p 125-167

Neubauer SC, Emerson D, Megonigal JP (2002) Life at the energetic edge: kinetics of circumneutral iron oxidation by lithotrophic iron-oxidizing bacteria isolated from the wetland-plant rhizosphere. Appl Environ Microbiol 68: 3988-3995

Nuckley DJ, Jinks RN, Battelle BA, Herzog ED, Kass L, Renninger GH, Chamberlain SC (1996) Retinal anatomy of a new species of bresiliid shrimp from a hydrothermal vent field on the Mid-Atlantic Ridge. Biol Bull (Woods Hole) 190:98-110 
Nye V, Copley J, Plouviez S (2012) A new species of Rimicaris (Crustacea: Decapoda: Caridea: Alvinocarididae) from hydrothermal vent fields on the Mid-Cayman Spreading Centre, Caribbean. J Mar Biol Assoc UK 92: 1057-1072

O'Neill PJ, Jinks RN, Herzog ED, Battelle BA, Kass L, Renninger GH, Chamberlain SC (1995) The morphology of the dorsal eye of the hydrothermal vent shrimp, Rimicaris exoculata. Vis Neurosci 12:861-875

Orcutt BN, Bradley JA, Brazelton WJ, Estes ER and others (2020) Impacts of deep-sea mining on microbial ecosystem services. Limnol Oceanogr 65:1489-1510

Pelli DG, Chamberlain SC (1989) The visibility of $350^{\circ} \mathrm{C}$ black-body radiation by the shrimp Rimicaris exoculata and man. Nature 337:460-461

Petersen JM, Ramette A, Lott C, Cambon-Bonavita MA, Zbinden M, Dubilier N (2010) Dual symbiosis of the vent shrimp Rimicaris exoculata with filamentous gamma- and epsilonproteobacteria at four Mid-Atlantic Ridge hydrothermal vent fields. Environ Microbiol 12: 2204-2218

* Petersen JM, Zielinski FU, Pape T, Seifert R and others (2011) Hydrogen is an energy source for hydrothermal vent symbioses. Nature 476:176-180

Polz MF, Cavanaugh CM (1995) Dominance of one bacterial phylotype at a Mid-Atlantic Ridge hydrothermal vent site. Proc Natl Acad Sci USA 92:7232-7236

* Polz MF, Robinson JJ, Cavanaugh CM, Van Dover CL (1998) Trophic ecology of massive shrimp aggregations at a midAtlantic Ridge hydrothermal vent site. Limnol Oceanogr 43:1631-1638

* Pond DW, Dixon DR, Bell MV, Fallick AE, Sargent JR (1997a) Occurrence of 16:2(n-4) and 18:2 (n-4) fatty acids in the lipids of the hydrothermal vent shrimps Rimicaris exoculata and Alvinocaris markensis: nutritional and trophic implications. Mar Ecol Prog Ser 156:167-174

* Pond DW, Dixon DR, Sargent JR (1997b) Wax-ester reserves facilitate dispersal of hydrothermal vent shrimps. Mar Ecol Prog Ser 146:289-290

* Pond DW, Segonzac M, Bell MV, Dixon DR, Fallick AE, Sargent JR $(1997 \mathrm{c})$ Lipid and lipid carbon stable isotope composition of the hydrothermal vent shrimp Mirocaris fortunata: evidence for nutritional dependence on photosynthetically fixed carbon. Mar Ecol Prog Ser 157: 221-231

Pond DW, Sargent JR, Fallick AE, Allen C, Bell MV, Dixon DR (2000a) $\delta^{13} \mathrm{C}$ values of lipids from phototrophic zone microplankton and bathypelagic shrimps at the Azores sector of the Mid-Atlantic Ridge. Deep Sea Res I 47: 121-136

Pond DW, Gebruk A, Southward EC, Southward AJ, Fallick AE, Bell MV, Sargent JR (2000b) Unusual fatty acid composition of storage lipids in the bresilioid shrimp Rimicaris exoculata couples the photic zone with MAR hydrothermal vent sites. Mar Ecol Prog Ser 198:171-179

Ponsard J, Cambon-Bonavita MA, Zbinden M, Lepoint G and others (2013) Inorganic carbon fixation by chemosynthetic ectosymbionts and nutritional transfers to the hydrothermal vent host-shrimp, Rimicaris exoculata. ISME J 7:96-109

Ramirez-Llodra E, Tyler PA, Copley JTP (2000) Reproductive biology of three caridean shrimp, Rimicaris exoculata, Chorocaris chacei and Mirocaris fortunata (Caridea: Decapoda), from hydrothermal vents. J Mar Biol Assoc UK 80:473-484
Ravaux J, Gaill F, Le Bris N, Sarradin PM, Jollivet D, Shillito B (2003) Heat-shock response and temperature resistance in the deep-sea vent shrimp Rimicaris exoculata. J Exp Biol 206:2345-2354

Ravaux J, Cottin D, Chertemps T, Hamel G, Shillito B (2009) Hydrothermal vent shrimps display low expression of heat-inducible hsp70 gene in nature. Mar Ecol Prog Ser 396:153-156

* Ravaux J, Léger N, Hamel G, Shillito B (2019) Assessing a species thermal tolerance through a multiparameter approach: the case study of the deep-sea hydrothermal vent shrimp Rimicaris exoculata. Cell Stress Chaperones 24:647-659

* Renninger GH, Kass L, Gleeson RA, Van Dover CL and others (1995) Sulfide as a chemical stimulus for deep-sea hydrothermal vent shrimps. Biol Bull (Woods Hole) 189: 69-76

*Rieley G, Van Dover C, Hedrick D, Eglinton G (1999) Trophic ecology of Rimicaris exoculata: a combined lipid abundance/stable isotope approach. Mar Biol 133:495-499

* Rittschof D, Forward RB Jr, Cannon G, Welch JM and others (1998) Cues and context: larval responses to physical and chemical cues. Biofouling 12:31-44

Roesijadi G (1992) Metallothioneins in metal regulation and toxicity in aquatic animals. Aquat Toxicol 22:81-113

* Rona PA, Klinkhammer G, Nelsen TA, Trefy JH, Elderfield $\mathrm{H}$ (1986) Black smokers, massive sulphides and vent biota at the Mid-Atlantic Ridge. Nature 321:33-37

Rosa R, Barracco M (2010) Antimicrobial peptides in crustaceans. Invertebr Surviv J 7:262-284

* Rousse N, Boulègue J, Cosson R, Fiala-Médioni A (1998) Bioaccumulation des métaux chez le mytilidae hydrothermal Bathymodiolus sp. de la ride médio-Atlantique. Oceanol Acta 21:597-607

* Salem H, Florez L, Gerardo N, Kaltenpoth M (2015) An outof-body experience: the extracellular dimension for the transmission of mutualistic bacteria in insects. Proc R Soc B 282:20142957

* Salerno JL, Macko SA, Hallam SJ, Bright M, Won Y, McKiness Z, Van Dover CL (2005) Characterization of symbiont populations in life-history stages of mussels from chemosynthetic environments. Biol Bull (Woods Hole) 208:145-155

Sandeman D, Kenning M, Harzsch S (2014) Adaptive trends in malacostracan brain form and function related to behaviour. In: Derby C, Thiel M (eds) Nervous systems and control behavior. The natural history of the Crustacea, Vol 3. Oxford University Press, New York, NY, p 11-48

* Sanders NK, Childress JJ (1990) Adaptations to the deepsea oxygen minimum layer: oxygen binding by the hemocyanin of the bathypelagic mysid, Gnathophausia ingens Dohrn. Biol Bull (Woods Hole) 178:286-294

* Sanders NK, Arp AJ, Childress JJ (1988) Oxygen binding characteristics of the hemocyanins of two deep-sea hydrothermal vent crustaceans. Respir Physiol 71:57-67

Schmidt M, Mellon D (2011) Neuronal processing of chemical information in crustaceans. In: Breithaupt T, Thiel $M$ (eds) Chemical communication in crustaceans. Springer Science + Business Media, New York, NY, p $123-147$

Schmidt C, Vuillemin R, Le Gall C, Gaill F, Le Bris N (2008a) Geochemical energy sources for microbial primary production in the environment of hydrothermal vent shrimps. Mar Chem 108:18-31 
Schmidt C, Le Bris N, Gaill F (2008b) Interactions of deepsea vent invertebrates with their environment: the case of Rimicaris exoculata. J Shellfish Res 27:79-90

Schmidt C, Corbari L, Gaill F, Le Bris N (2009) Biotic and abiotic controls on iron oxyhydroxide formation in the gill chamber of the hydrothermal vent shrimp Rimicaris exoculata. Geobiology 7:454-464

Scott K, Boller A, Dobrinski K, Le Bris N (2012) Response of hydrothermal vent vestimentiferan Riftia pachyptila to differences in habitat chemistry. Mar Biol 159:435-442

Scott JJ, Breier JA, Luther GW III, Emerson D (2015) Microbial iron mats at the Mid-Atlantic Ridge and evidence that Zetaproteobacteria may be restricted to iron-oxidizing marine systems. PLOS ONE 10:e0119284

Segonzac M (1992) Les peuplements associés à l'hydrothermalisme océanique du Snake Pit (dorsale médioAtlantique, $23^{\circ} \mathrm{N}, 3480 \mathrm{~m}$ ): composition et microdistribution de la mégafaune. C R Acad Sci III 314:593-600

Segonzac M, de Saint-Laurent M, Casanova B (1993) L'énigme du comportement trophique des crevettes Alvinocarididae des sites hydrothermaux de la dorsale médio-atlantique. Cah Biol Mar 34:535-571

Segonzac M, Comtet T, Chevaldonné P (1997) Epibiosis of two invertebrate species associated to oceanic hydrothermalism: an example of adaptative convergence. Cah Biol Mar 38:139-140

* Shank TM, Lutz RA, Vrijenhoek RC (1998) Molecular systematics of shrimp (Decapoda: Bresiliidae) from deepsea hydrothermal vents. I. Enigmatic 'small orange' shrimp from the Mid-Atlantic Ridge are juvenile Rimicaris exoculata. Mol Mar Biol Biotechnol 7:88-96

Khank TM, Black MB, Halanych KM, Lutz RA, Vrijenhoek RC (1999) Miocene radiation of deep-sea hydrothermal vent shrimp (Caridea: Bresiliidae): evidence from mitochondrial cytochrome oxidase subunit I. Mol Phylogenet Evol 13:244-254

Shillito B, Le Bris N, Hourdez S, Ravaux J and others (2006) Temperature resistance studies on the deep-sea vent shrimp Mirocaris fortunata. J Exp Biol 209:945-955

Shillito B, Hamel G, Duchi C, Cottin D and others (2008) Live capture of macrofauna from $2300 \mathrm{~m}$ depth, using a newly designed pressurized recovery device. Deep Sea Res I 55:881-889

Shillito B, Gaill F, Ravaux J (2014) The Ipocamp pressure incubator for deep-sea fauna. J Mar Sci Technol 22: 97-102

* Shillito B, Ravaux J, Sarrazin J, Zbinden M, Barthélémy D, Sarradin P (2015) Long-term maintenance and public exhibition of deep-sea fauna: the AbyssBox project. Deep Sea Res I 121:137-145

Steel C (1993) Storage and translocation of integumentary calcium during the moult cycle of the terrestrial isopod Oniscus asellus (L.). Can J Zool 71:4-10

Stegner MEJ, Stemme T, Iliffe TM, Richter S, Wirkner CS (2015) The brain in three crustaceans from cavernous darkness. BMC Neurosci 16:19

Stephens GC (1988) Epidermal amino acid transport in marine invertebrates. Biochim Biophys Acta 947:113-138

Tasiemski A, Jung S, Boidin-Wichlacz C, Jollivet D and others (2014) Characterization and function of the first antibiotic isolated from a vent organism: the extremophile metazoan Alvinella pompejana. PLOS ONE 9:e95737

Taylor VF, Jackson BP, Siegfried MR, Navratilova J, Francesconi KA, Kirshtein J, Voytek M (2012) Arsenic speciation in food chains from mid-Atlantic hydro- thermal vents. Environ Chem 9:130-138

* Teixeira S, Cambon-Bonavita MA, Serrao E, Desbruyères D, Arnaud-Haond S (2011) Recent population expansion and connectivity in the hydrothermal shrimp Rimicaris exoculata along the Mid-Atlantic Ridge. J Biogeogr 38: 564-574

* Teixeira S, Serrao EA, Arnaud-Haond S (2012) Panmixia in a fragmented and unstable environment: the hydrothermal shrimp Rimicaris exoculata disperses extensively along the Mid-Atlantic Ridge. PLOS ONE $7(6)$ : e38521

* Teixeira S, Olu K, Decker C, Cunha R and others (2013) High connectivity across the fragmented chemosynthetic ecosystems of the deep Atlantic Equatorial Belt: efficient dispersal mechanisms or questionable endemism? Mol Ecol 22:4663-4680

Truchot JP (1992) Respiratory function of arthropod hemocyanins. In: Mangum C (ed) Blood and tissue oxygen carriers. Springer Verlag, Berlin, p 377-410

* Tyler PA, Dixon DR (2000) Temperature/pressure tolerance of the first larval stage of Mirocaris fortunata from Lucky Strike hydrothermal vent field. J Mar Biol Assoc UK 80: 739-740

* Tyler PA, Young CM (2003) Dispersal at hydrothermal vents: a summary of recent progress. Hydrobiologia 503:9-19

Van Dover CL (2000) The ecology of deep-sea hydrothermal vents. Princeton University Press, Princeton, NJ

V Van Dover CL (2011) Tighten regulations on deep-sea mining. Nature 470:31-33

Van Dover CL (2014) Impacts of anthropogenic disturbances at deep-sea hydrothermal vent ecosystems: a review. Mar Environ Res 102:59-72

*Van Dover CL, Fry B, Grassle JF, Humphris S, Rona PA (1988) Feeding biology of the shrimp Rimicaris exoculata at hydrothermal vents on the Mid-Atlantic Ridge. Mar Biol 98:209-216

*Van Dover CL, Szuts EZ, Chamberlain SC, Cann JR (1989) A novel 'eyeless' shrimp from hydrothermal vents of the Mid-Atlantic Ridge. Nature 337:458-460

*Van Dover CL, Reynolds GT, Chave AD, Tyson JA (1996) Light at deep-sea hydrothermal vents. Geophys Res Lett 23:2049-2052

*Van Dover CL, German CR, Speer KG, Parson LM, Vrijenhoek RC (2002) Evolution and biogeography of deep-sea vent and seep invertebrates. Science 295:1253-1257

*Vereshchaka AL (1996) A new genus and species of caridean shrimp (Crustacea: Decapoda: Alvinocarididae) from North Atlantic hydrothermal vents. J Mar Biol Assoc UK 76:951-961

* Vereshchaka AL (1997) Comparative morphological studies on four populations of the shrimp Rimicaris exoculata from the Mid-Atlantic Ridge. Deep Sea Res I 44: 1905-1921

Vereshchaka A, Vinogradov G, Ivanenko V (1998) General properties of the reproductive biology of some hydrothermal Crustacea (shrimp, amphipods, copepods). Dokl Biol Sci 360:269-270

*Vereshchaka AL, Vinogradov GM, Lein AY, Dalton S, Dehairs F (2000) Carbon and nitrogen isotopic composition of the fauna from the Broken Spur hydrothermal vent field. Mar Biol 136:11-17

Vereshchaka AL, Kulagin DN, Lunina AA (2015) Phylogeny and new classification of hydrothermal vent and seep shrimps of the family Alvinocarididae (Decapoda). PLOS ONE 10:e0129975 
Vrijenhoek C (2010) Genetic diversity and connectivity of deep-sea hydrothermal vent metapopulations. Mol Ecol 19:4391-4411

Waite DW, Vanwonterghem I, Rinke C, Parks DH and others (2017) Comparative genomic analysis of the class Epsilonproteobacteria and proposed reclassification to Epsilonbacteraeota (phyl. nov.). Front Microbiol 8:682

Waite DW, Vanwonterghem I, Rinke C, Parks DH and others (2018) Addendum: Comparative genomic analysis of the class Epsilonproteobacteria and proposed reclassification to Epsilonbacteraeota (phyl. nov.). Front Microbiol 9: 772

Watabe H, Hashimoto J (2002) A new species of the genus Rimicaris (Alvinocarididae: Caridea: Decapoda) from the active hydrothermal vent field, 'Kairei Field,' on the Central Indian Ridge, the Indian Ocean. Zool Sci 19:1167-1174

Wharton D, Jinks R, Herzog E, Battelle B, Kass L, Renninger G, Chamberlain S (1997) Morphology of the eye of the hydrothermal vent shrimp Alvinocaris markensis. J Mar Biol Assoc UK 77:1097-1108

Wheeler AJ, Murton B, Copley J, Lim A and others (2013) Moytirra: discovery of the first known deep-sea hydrothermal vent field on the slow-spreading Mid-Atlantic Ridge north of the Azores. Geochem Geophys Geosyst 14:4170-4184

Williams A, Rona P (1986) Two new caridean shrimps (Bresiliidae) from a hydrothermal field on the Mid-Atlantic

Editorial responsibility: Rochelle D. Seitz, Gloucester Point, Virginia, USA
Ridge. J Crustac Biol 6:446-462

* Wirsen C, Jannasch HW, Molyneaux S (1993) Chemosynthetic microbial activity at Mid-Atlantic Ridge hydrothermal vent sites. J Geophys Res 98:9693-9703

Wolff GH, Thoen HH, Marshall J, Sayre ME, Strausfeld NJ (2017) An insect-like mushroom body in a crustacean brain. eLife 6:e29889

* Yang Y, Sun J, Sun Y, Kwan YH and others (2020) Genomic, transcriptomic, and proteomic insights into the symbiosis of deep-sea tubeworm holobionts. ISME J 14:135-150

K Zbinden M, Cambon-Bonavita MA (2003) Occurrence of Deferribacterales and Entomoplasmatales in the deepsea shrimp Rimicaris exoculata gut. FEMS Microbiol Ecol 46:23-30

K Zbinden M, Le Bris N, Gaill F, Compère P (2004) Distribution of bacteria and associated minerals in the gill chamber of the vent shrimp Rimicaris exoculata and related biogeochemical processes. Mar Ecol Prog Ser 284:237-251

* Zbinden M, Shillito B, Le Bris N, De Vilardi de Montlaur C and others (2008) New insights on the metabolic diversity among the epibiotic microbial community of the hydrothermal shrimp Rimicaris exoculata. J Exp Mar Biol Ecol 359:131-140

* Zbinden M, Berthod C, Montagné N, Machon J and others (2017) Comparative study of chemosensory organs of shrimp from hydrothermal vent and coastal environments. Chem Senses 42:319-331

Submitted: February 25, 2020; Accepted: August 11, 2020 Proofs received from author(s): October 8, 2020 